\title{
Research Paper \\ The effect of various types of visual and kinesthetic mental imagery on learning of throwing skill from below the shoulder og children
}

\author{
Farzad Maleki ${ }^{1}$, Ali Kashi ${ }^{2}$, Elahe Asareh ${ }^{3}$, Narjes Khatoon Zarooni ${ }^{4}$ \\ 1. Assistant Professor, Department of Physical Education, Payame Noor University, Iran. \\ 2. Assistant Professor, Department of Motor Behaviour, Sport Science Research Institute of Iran (SSRI), Tehran, Iran. \\ 3. Ph.D. in Motor Behavior, Islamic Azad University, Iran. \\ 4. M.A. of Physical Education, Payame Noor University, Iran.
}

\begin{abstract}
Citation: Maleki F, Kashi F, Asareh E, Narjes Khatoon Z. Sustainable well-being: The effect of various types of visual and kinesthetic mental imagery on learning of throwing skill from below the shoulder og children. J of Psychological Science. 2021; 20(103): 1193-1211.
\end{abstract}

URL: https://psychologicalscience.ir/article-1-1126-fa.html
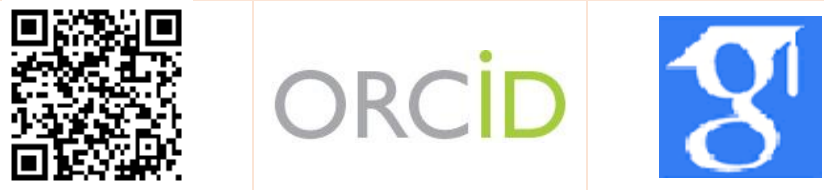

$\underline{10.52547 / J P S .20 .103 .1193}$
A R T I C L E I N F O

\section{Keywords:}

visual mental imagery, motor mental imagery, imagery vividness, retention, transfer

Received: 25 Jan 2021 Accepted: 20 Feb 2021 Available: 23 Sep 2021
A B S T R A C T

Background: Mental imagery, incudes visualizing or motor cognitive review without physical components, is one of the sychological methods to improve performance and facilitate skills. Although the applied model has shown that there is an interaction between the type of imagery and and the ability of imagery and motor output is increased by bettter performance, there is a research gap whether neural representation causes different behavioral effects among children through vividness of imagery.

Aims: The aim of present study was the effect of various types of visual and kinesthetic mental imagery on learning of close motor skill in children as well as the relationship between the ability to imagery vividness and motor performance.

Methods: the research was quasi-experimental with a multi-group pre-test- post-test design along with a control group. The statistical population of the study was all female students aged 8 to 10 years in Ahvaz. 90 female students were deployed by random sampling method available in 6 groups of 15 people of physical practice (PPG), visual imagery (VIG), kinesthetic imagery (KIG), visual imagery and physical practice composition (VIPPG), kinesthetic imagery and physical practice composition (KIPPG), and control group (CG). Each participant performed 35 throws in 7 blocks of 5 trials in pre-test 5 , acquisition 20 , post-test 5 , and transfer 5 . The ability of imagery vividness of participants was measured by questionnaire of motor imagery vividness (Isak et al., 1986). Data analysis was performed using mixed variance analysis (phase) $3 \times$ (group) 6 and Pearson correlation by Spss 21 software.

Results: The performance of the various imagery groups was equal to that of physical practice group in the post-test (retention) phase. The results at the transfer phase showed that the combination of mental imagery with physical training had significantly higher performance than the other groups. The results of the research also showed that the visual mental imagery and kinesthetic imagery groups showed equal performance in the transfer and retention stages (KIG=VIG, KIPPG=VIPPG). The results of the research did not show any relationship between the ability of imageryvividness and motor performance.

Conclusion: The results of the research showed that children have the ability to visualize motor skills the same as adults. However, children ( 8 to 10 years of age) do not have the ability to separate the visual and kinesthetic imagery and understand their differences. The results also showed that the ability to have a vivid imagery has no significant effect on children's motor performance.

* Corresponding Author: Farzad Maleki, Assistant Professor, Department of Physical Education, Payame Noor University, Iran.

E-mail: f.maleki@ut.ac.ir

Tel: (+98) 9166979443

2476-5740/ (C) 2021 The Authors. This is an open access article under the CC BY-NC-ND license

(https://creativecommons.org/licenses/by-nc/4.0/). 


\section{Extended Abstract}

\section{Introduction}

One of these psychological methods that is often used by teachers and trainers to facilitate the learning of sports skills is mental imagery (Malder, 2007). Mental imagery includes visualizing or motor cognitive review without physical performance, and its frequent demonstration and effectiveness make it a valuable strategy for improving performance. In general, mental imagery is the representation of currently nonexistent or absent objects or events. This imagery is a type of conceptual imagery that is based on perception in memory (Kastoriadis, 2016: quoted by Lajevardi, Mirza Hosseini \& Monirpour, 2018). Accordingly, it is widely accepted that the use of imagery enhances performance (Williams, Cumming, Notomins, Nordin, \& Ramsey, 2012). According to researchers, using mental imagery to simulate movements can facilitate performance by practicing areas of the brain in common between physical performance and mental imagery (Gannis, Thompson, \& Kasselin, 2004). As a result, the primary purpose of the present study was to compare the effects of combining mental imagery with physical exercise as well as the impact of physical exercise itself on learning closed motor skills in children aged 8 to 10 years.

Landers believes that imagery is primarily a visual experience (Marltz, 1993). However, other senses may be involved. The sensory aspects of imagery include: visual, kinetic, auditory, tactile, olfactory, and taste imagery (Willie \& Greenleaf, 2001). In addition, the nature of the task affects the use of different sensory aspects. Visual imagery is the process by which a person views and feels scenes or images in his mind (Glynn, 2000). Kinetic imagery is the ability to visualize the movement sensation of the body and other bodily senses (Abma, Eri, and Relia, 2002). Several studies have distinguishedbetween kinesthetic and visual imagery (Frey, 2003). Although most studies indicate the effects of mental imagery on motor skills and performance enhancement, the discovery of such results (differences in mental and visual imagery) in children is rare. Therefore, as a second objective, it was important to determine which form of mental imagery (visual versus kinesthetic) has the greatest effect on the retention and transfer of motor task. Chang and Hardy (2016) in examining the applied model of mental image use showed that there is an interaction between the type of imagery and the ability to visualize. Although, different neural activities have recently been studied in neuroimaging studies, and these studies have shown that motor output is enhanced by better performance in imagery ability (Williams et al., 2013), the mechanism showing that neural representation causes different behavioral effects due to imaging clarity has not yet been proven. Thus, the third purpose of the present study is to determine the effects of motor imagery vividness on motor performance. In other words, do highervividness imagery leads to better performance than lower- vividness imagery in performance on closed motor skill?

\section{Method}

The research was an applied quasi-experimental study with a multi-group pre-test post-test design along with a control group. Statistical population of the study consisted of all right-handed female students aged 8 to 10 years in Ahvaz primary schools. Out of which 90 participants were purposefully and accessibly selected according to the research type and then they were randomly assigned into 6 groups of 15 subjects. The participants answered the 24-item the Vividness of Movement Imagery Questionair (VMIQ) honestly. This questionnaire, which examines the ability of visual imagery, was first introduced by Isaac, Marquez, and Russell (1986) to fill a void in the literature relating

Before performing the throw, each subject was informed about how to perform the movement and the necessary instructions and training were provided for each group as well. The subject was first asked to stand behind the throw line 2 meters of the target. The target consisted of three concentric circles with diameters of 20, 40 and $60 \mathrm{~cm}$. in addition, the center of the target (center of the circles) is at a distance of $130 \mathrm{~cm}$ from the ground. Imagery guidelines and instructions were pre-prepared by the tape recorder. In general, each participant performed 35 throws in 7 blocks of 5 trials in pre-test 5 , acquisition 20, post- 


\section{Monthly Journal of Psychological Science}

Vol. 20, No. 103, Autumn(October) 2021

test 5 , and transfer 5 . In the pre-test, practice and posttest $\mathrm{s}$, each participant throws a throw under the shoulder with the left hand using a $50 \mathrm{~g}$ yellow tennis ball towards the target, which is located at a distance of $200 \mathrm{~cm}$. The target is the same circles with diameters of 60,40 , and $20 \mathrm{~cm}$. But during the transfer, all participants throw a $150 \mathrm{~g}$ ball at a target $250 \mathrm{~cm}$ away. The target here is the same 20, 40, 60 $\mathrm{cm}$ circles. In the acquisition, the first group (Physical Practice Group) throws the ball 20 times under the shoulder towards the target. The second group (Visual Imagery Group) throws the tennis ball 10 times mentally under the shoulder according to these instructions (hold the tennis ball with your left hand, close your eyes, think very clearly that the tennis ball is moving towards the center of the target, open your eyes at the end of the movement). The third group (kinesthetic Imagery Group) throws the tennis ball mentally under the shoulder 20 times according to these instructions (hold the tennis ball with your left hand, close your eyes, exert force to the muscles of your left hand to throw the ball with a very clear feeling, open your eyes at the end of the movement). The fourth group (physical practice and visual imagery composition): Participants in this group perform 10 throws physically as the first group and they performs 10 other throws in the form of visual imagery as the second group. The fifth group (physical practice and kinesthetic imagery): Participants in this group perform 10 throws physically as the first group and 10 other throw trials in the form of physical imagery as the third group. The sixth group (Control Group): Participants in this group do not perform any throws at this

Thus, the required data was collected; finally, the findings were analyzed using SPSS software (version 21) and combined analysis of variance test with repeated measures.

\section{Results}

Mean and standard deviation of throwing scores obtained from under-shoulder throw in different groups in pre-test, post-test and transfer $\mathrm{s}$ are presented in Table 1 below.

Table 1. Mean and standard deviation of participants in performing under-shoulder throw in each Experimental group in different s of the

\begin{tabular}{cccccccc}
\hline \multirow{2}{*}{ Groups } & \multicolumn{9}{c}{ Pret- test } & \multicolumn{2}{c}{ Post-test Retention } & \multicolumn{3}{c}{ Transfer } \\
\cline { 2 - 8 } & $\mathrm{F}$ & $\mathrm{M}$ & SD & $\mathrm{M}$ & SD & $\mathrm{M}$ & SD \\
\hline VIPPG & 15 & 7.46 & 3.02 & 10.00 & 2.23 & 7.00 & 1.64 \\
KIG & 15 & 7.60 & 2.44 & 8.80 & 2.23 & 6.60 & 2.58 \\
VIG & 15 & 6.93 & 2.18 & 9.33 & 1.95 & 7.73 & 1.70 \\
KIPPG & 15 & 7.26 & 2.02 & 9.40 & 2.52 & 8.53 & 2.66 \\
VIPPG & 15 & 6.86 & 1.68 & 9.66 & 1.75 & 9.06 & 1.98 \\
CG & 15 & 7.26 & 2.25 & 7.60 & 1.68 & 6.60 & 1.68 \\
\hline
\end{tabular}

In order to compare the participants' performance in different groups as well as through various s of the study, combined analysis of variance test was used. The results of the combined analysis of variance test showed that the main effect of the $\mathrm{s}(\mathrm{P}=0.2001=$ $0.684, \mathrm{~F}=2.168 / 197)$ was significant; But the main effect of the group $(\mathrm{P}==0.1773, \mathrm{P}=0.177, \mathrm{n}=570$ $=84.5 \mathrm{~F})$ was not significant. In addition, the interaction of phases and groups $(P=0.137=0.131$, $\mathrm{P}=2.586=168,10 \mathrm{~F})$ is also significant. Because the interactive effect (phases * group) is significant, the main effects are omitted. Then, the intragroup analysis of variance design with repeated measures on (598) (10) 598), a significant difference existed between different phases ofthe test. However, no the factor was used to determine the effect of different experimental groups on the rate of the under shoulder throw in different phases. According to alpha modulation at the level of 0.008 , the results of intragroup analysis of variance test with repeated measures on the factor showed that in the Physical Practice Group $(\mathrm{p}=0.001$ and $\mathrm{F}=12.276(28$ and 2$))$, the Visual Imagery Group ( $\mathrm{p}=0.023$ and $\mathrm{F}=4.333$ (F (28 and 2)), Motor Imagery Group ( $\mathrm{p}=0.002$ and $\mathrm{F}=7.853$ (F.22)), Visual Imagery and Physical Practice Composition Group $\mathrm{P}=0.031$ and $\mathrm{F}=3.937$ (28 and 2) (F), Movement Imagery and Physical Practice Composition Group $(\mathrm{p}=0.001$ and $\mathrm{F}=10$ significant difference was observed in the control group $(\mathrm{p}=0.140$ and $\mathrm{F}=2.112(28,2))$. To 


\section{Monthly Journal of Psychological Science}

investigate the location of the differences, the Benfroni follow-up test was used, the results indicated that there is a significant difference between the scores of pre-test and post-test phases in all experimental groups (except CG and VIG). Such that, VIPPG, KIPPG, KIG, and SPPG scores in the posttest phase is significantly higher than the pre-test phase. Also, only in KIPPG group, a significant difference was found between the pretest phase and transfer phase while no significant difference was found between the pre-test phase and transfer phase in other groups.

Having examined the intragroup differences, considering the significance of the interaction between phases and groups $(\mathrm{P}=0.007,168,10 \mathrm{~F}=$ 556.556), one-way analysis of variance (ANOVA) test was used to examine the differences between groups in different phases of measurement. According to alpha modulation $(\mathrm{p}=0.017)$, the results showed that in the post-test phase, there was a significant difference between the performance of the experimental groups $(\mathrm{p}=0.041$ and $\mathrm{F}=2.443(\mathrm{~F}, 84$, $5)$ ). The results of Tukey post hoc test showed that the performance of all experimental groups (VIPPG, KIPPG, KIG, SPPG) was significantly higher than the control group $(\mathrm{p}=0.002, \mathrm{p}=0.027, \mathrm{p}=0.022$ and $\mathrm{p}=0.009$ ). But no significant difference was found between the performance of VIG group and control group. While at this phase (post-test) the performance of all experimental groups (VIPPG, KIPPG, KIG, VIG, SPPG) were equal. In addition, there was a significant difference between the performance of the experimental groups in the transfer $(\mathrm{p}=0.004$ and $\mathrm{F}$ $=3.709(F, 84,5))$. The results of Tukey post hoc test indicated that the performance of experimental groups (VIPPG, KIPPG) was significantly higher than SPPG groups $(\mathrm{p}=0.048$ and $\mathrm{p}=0.008)$, VIG ( $\mathrm{p}$ $=0.013$ and $p=0.002)$ and control group $(\mathrm{p}=0.013$ and $p=0.002$ ) but there was no significant difference between the performance of experimental groups (VIPPG, KIPPG) and KIG. Moreover, no significant difference existed between other experimental groups. Pearson correlation coefficient was used to examine the relationship between mental imagery and motor function in the pre-test, post-test (retention) and transfer phases; the results showed that no
Vol. 20, No. 103, Autumn(October) 2021

significant relationship existed between the ability of mental imagery and performance in pre-test $(\mathrm{p}=$ $0.985, r=-0.0)$, post-test $(p=0.055, r=0.203)$ and retention phases $(\mathrm{p}=0.375, \mathrm{R}=0.095)$.

\section{Conclusion}

The results showed that the level of performance and mental imagery of the participants were equal in different groups in pre-test phase. The initial similarity between the level of motor skills and the ability of mental imagery of the participants was confirmed. In addition, the performance achieved in the post-test (retention) phase by the imagery groups (VIG, KIG, VIPPG, KIPPG) was equal to that achieved in the physical practice group (PPG) confirming the results reported by Gold et al. (2002) and Cole et al. (1992).

The results of Dasti' (1989) and Taktek's (2004) research also demonstrated the equality of mental imagery and physical practice. Theses results are in line with the results of the present study and confirm it as well, so it can be explained that: 1. Mental and physical training use a common mechanism that is responsible for the temporary organization of movements. 2. Movements that are perfomed either mentally or physically are controlled through the same general movement program. Holmes and Klins (2001) reported such results by the so-called terms "behavioral document for performance equality" between mental imagery and physical practice. Furthermore, Dasti's (1989) and Malvin et al.'s (2003) findings claimed that mental imagery and physical practice have common general neural mechanisms and hence play the role in the performance of motor tasks.

The results obtained in the transfer phase showed that the participants in mental imagery and physical practice composition group (KIPPG, VIPPG) outperformed the participants in the VIG, PPG and $\mathrm{CG}$ groups. In this regard, in his research, Overdrf (2004) also demonstrated that the combination of mental and physical practice can be more effective than the separate use of physical practice or mental practice. Generally, performing 10 physical practice trials combined with 10 mental imagery trials could significantly increase behavioral, peripheral, and external function (Holmes \& Collins, 2001). 


\section{Monthly Journal of Psychological Science}

Vol. 20, No. 103, Autumn(October) 2021

If it is accepted, then why participants in mental imagery combined with visual or physical practice group (KIPPG or VIPPG) do not perform better motor performance during the retention (post-test)? Schmidt (1975) in his motor schema theory assumes that during the acquisition, variable practice leads to lower performance compared to physical practice, while during the transfer it leads to better learning. Such results can be explained by the fact that variable practice leads to a variable and general motor schema that has a better potential for adaptation to the new motor skills and is very similar, not identical, to the transfer task. This is probably true about the combination of mental imagery and physical practice (VIPPG or KIPPG). During the transfer and at the levels of force and space parameters, participants in KIPPG and VIPPG groups had the opportunity to develop a variable motor scheme so that these changes could continue throughout the Because the performance achieved in each group combined with physical practice imagery (VIPPG or KIPPG) was equal to the specific physical practice group (SPPG) in the retention but it was significantly better than the specific physical practice group (SPPG) in the transfer phase. Therefore, the first hypothesis of this research is formed.

The results of the present study also indicated that the mental imagery groups showed the same motor function in the transfer and retention phases when the imagery instructions emphasized visual and motor components $(\mathrm{KIG}=\mathrm{VIG}$ and $\mathrm{KIPPG}=\mathrm{VIPPG})$. It seems that the motor imagery instructions (KIPPG, $\mathrm{KIG}$ ) and visual (VIG, VIPPG) instructions seem to emphasize the force required to throw the ball (it is clearly felt that there is a $50 \mathrm{~g}$ tennis ball throwing force in the muscles of the left hand) or the movement (speed) of that ball (it is clearly thought that the tennis ball moves towards the center of the target located at $200 \mathrm{~cm}$ ), respectively. Thus, the performance equality obtained between visual and motor mental imagery can be accounted for by the fact that they contain parameters similar to motor task that emphasize the body's perception (feeling) as producing the force (or speed) required to perform the movement (Frey \& Morizot , 2000).
The results of the present study support the findings reported by Frey and Morizot (2000). The lack of any difference between the conditions of motor and visual imagery can be attributed to the fact that because the participants of the objective operation (Piaget \& In Holder (a, b), 1966 \& 1981) were specifically between the ages of 8 and 10, they do not have the ability to distinguish visual and motor imagery, and instead of using both visual and motor imagery, they considered it as a single form of imagery. It may also be possible that the imagery instructions direct the participants' attention to the imagery process rather than the type of imagery (body versus ball). Therefore, the lack of any difference between motor and visual imagery conditions indicates that the second hypothesis of the research is not supported.

The results demonstrated that there was no positive relationship between the participants' scores in the Vividness of Motor Imagery Questionnaire (VMIQ) and their motor performance in the pre-test, post-test (retention) and transfer phases. These results rejected the third hypothesis of this study. The third hypothesis of the study claimed that individuals with stronger imagery ability performed better than those with weaker imagery ability during the performance of a closed motor skill. However, these results were confimed by the results of previous research by (2005). However, the main reason for the lack of correlation between motor performance imagery capabilities is related to poor clarity of the Vividness of Movement Imagery Questionnaire (VMIQ).

Therefore, the lack of correlation between the Vividness of Movement Imagery questionnaire (VMIQ) and the participants' performance is probably more related to the fact that this questionnaire does not have the necessary validity to be used in children of 8 to 10 years. Accordingly, the results of this study confirm the findings of researchers such as (Taktek and Rigai, 2005; Taktek et al., 2004). In addition it suggest that, although this process can be applied to a wide range of participants (as in Research by Isaac et al., 1986 ) but the Vividness of Movement Imagery questionnaire (VMIQ) should be adapted for children aged 8 to 10 years. Taktek et al. (2004) as well as Taktak and Rigjai 


\section{Ethical Considerations}

Compliance with ethical guidelines: This article is taken from the research conducted in the Physical Education Research Institute.

Funding: This study is sponsored by the Physical Education Research Institute.

Authors' contribution: The first author is the main researcher of this study. The second author was the supervisor and the third and fourth authors were helpful in selecting samples, communicating with the subjects, and collecting data.

Conflict of interest: The authors do not state any conflict of interest in this study.

Acknowledgments: I would like to express my gratitude to the supervisor, research colleagues, officials of the Physical Education Research Institute, students participating in this research and their teachers who helped us to carry out this research as well as possible. 
تأثير شيوههاى مختلف تصويرسازى ذهنى ديدارى و حر كتى بر يادكيرى مهارت يرتاب از زير شانه كود كان

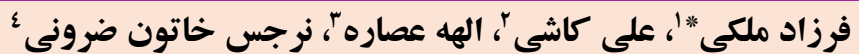

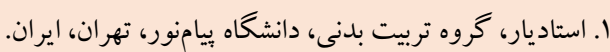

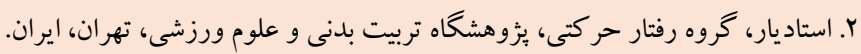

r. دانشجوى دكترى تربيت بدنى دانشاه آزاد اسلامى، تهران، ايران.

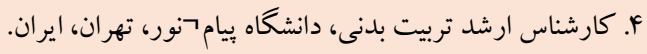

\section{جكيده}

زمينه: تصويرسازى ذهنى شامل تجسم يا مرور شناختى حركت بدون اجزاى فيزيكى، يكى از اين شيوههاى روانى براى ارتقا عملكرد و

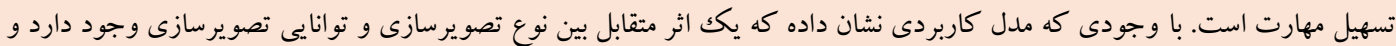

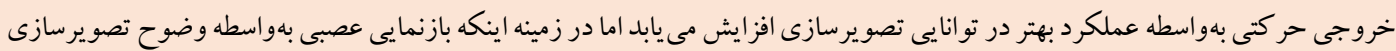

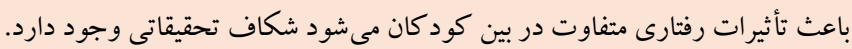
هدف: : هدف تحقيق حاضر تأثير انواع مختلف تصويرسازى ذهنى ديدارى و حر كتى بر ياد گيرى مهارت حركتى بسته، همجنين ارتباط بين

$$
\text { توانايى وضوح تصويرسازى و عملكرد حر كت در كود كان بود. }
$$

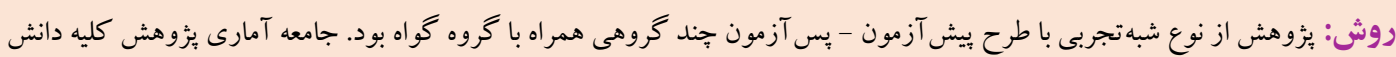

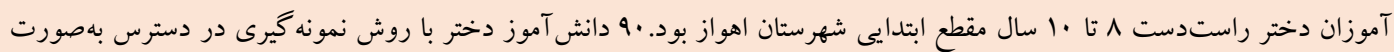

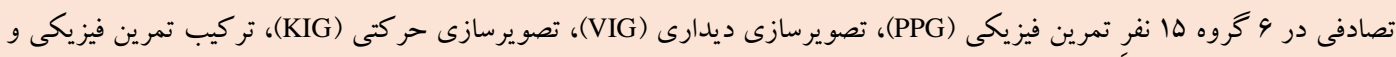

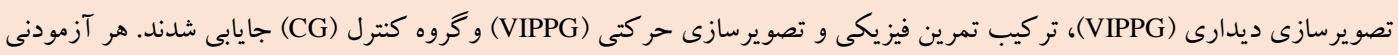

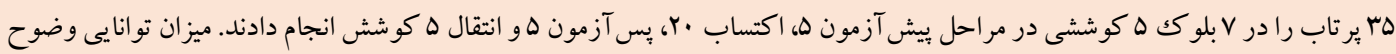

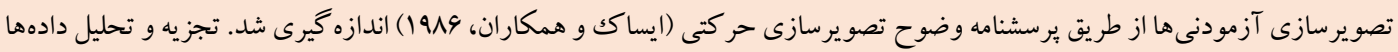

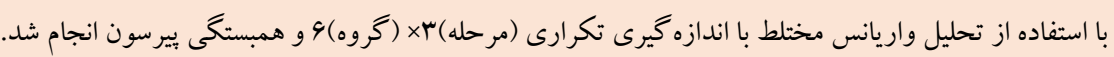

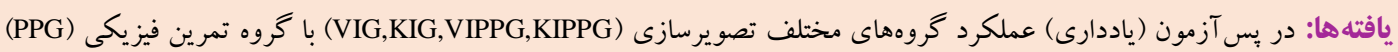
برابر بود. نتايج مرحله انتقال نشان داد كه تركيب تصويرسازى ذهنى با تمرين فيزيكى (KIPPG,VIPPG) بهطور قابلملاحظهاى عملكرد

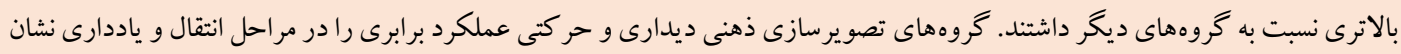

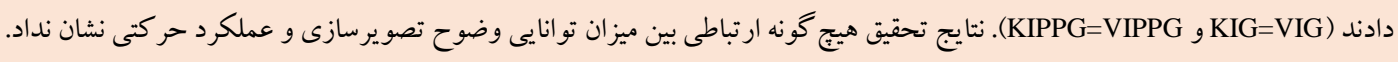
نتيجه كيرى: نتايج يثوهش نشان داد كود كان نيز مانند بزركسالان توانايى تصوير سازى ذهنى مهارتهاى حركتى را دارند. اما كود كان

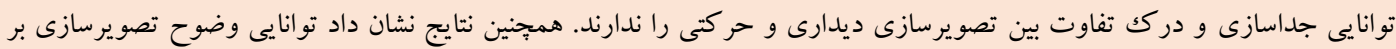
عملكرد حركتى در اين مقطع سنى (1 تا · اسال) تأثير ندارد.
مشخصات مقاله

كليدوازهها: تصويرسازى ذهنى ديدارى، تصويرسازى ذهنى حركتى، وضوح تصويرسازى،

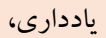
انتقال

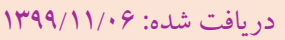

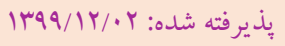

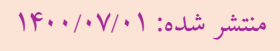

* نويسنده مسئول: فرزاد ملكى، استاديار، گروه تربيت بدنى، دانشگاه يِام حنور، تهران، ايران. رايانامه: f.maleki@ut.ac.ir 


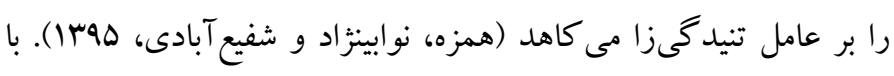

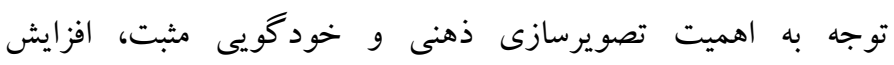
تصويرسازى ذهنى و افكار مثبت در ورزشكار سبب كاهش اضطراب شناختى و جسمانى در ورزشكار مى شود كه در نتيجه منجر به تسهيل

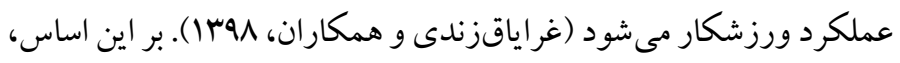

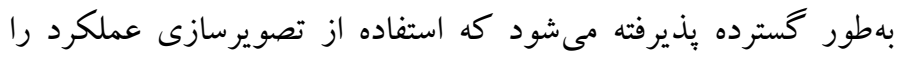

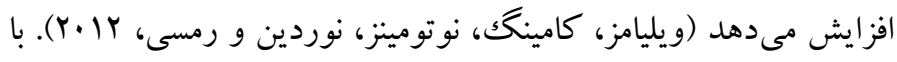

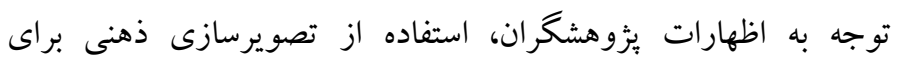
شبيه سازى حر كات با تمرين دادن مناطقى از مغز كه بين اجراى فيزيكى و وهرو

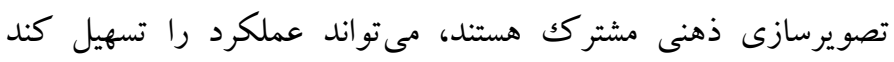

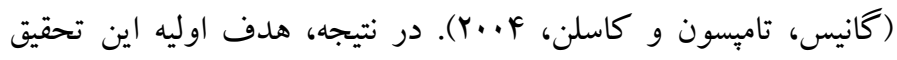
مقايسه اثرات تر كيب تصويرسازى ذهنى با تمرين فيزيكى و تمرين فيزيكى تهى

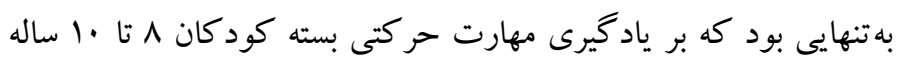

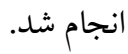
مرور ادبيات رفتار حر كتى نشان مىدهد كه تصويرسازى داراى دو جنبه يا بعد درونى و بيرونى است (موريس، هـ(Y). تصويرسازى درونى شامل

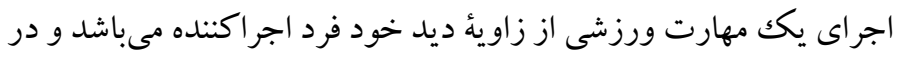

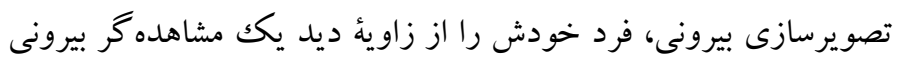

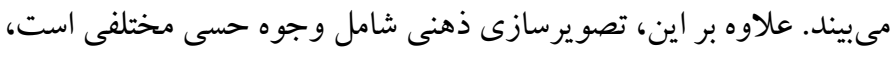

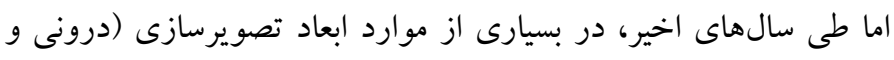

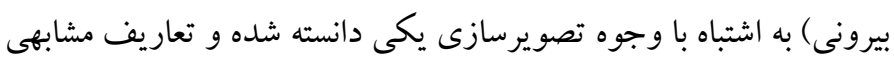

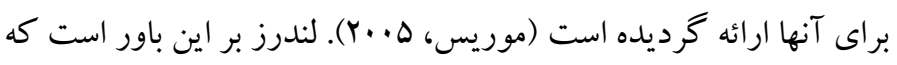

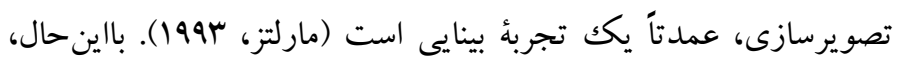

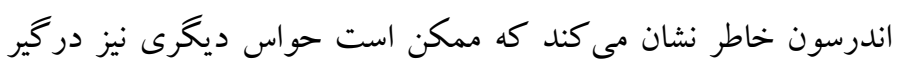

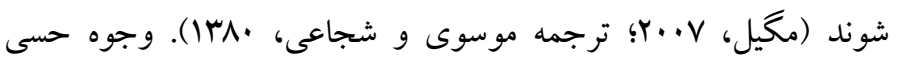

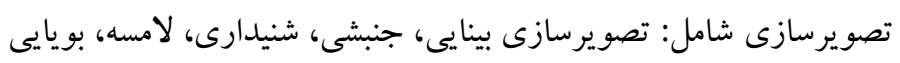

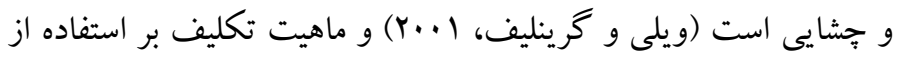

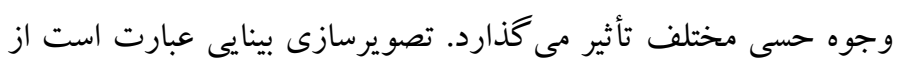

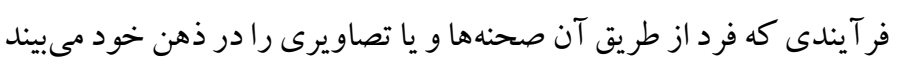

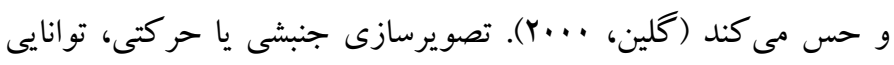
تصويرسازى احساس حركت بدن و ساير حواس بدنى مىباشد (ابما، ارى

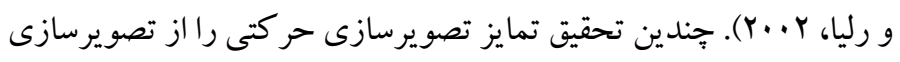

dolo

يكى از اهداف اصلى در يادگيرى حر كتى، شناخت متغيرهايى است كه در

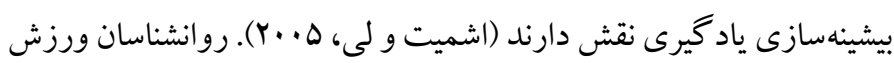

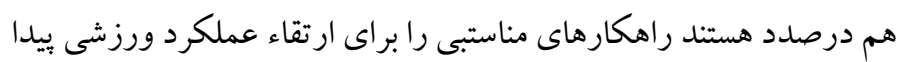

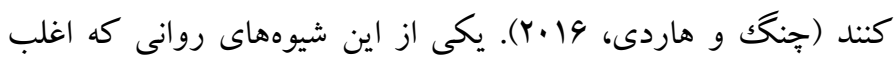

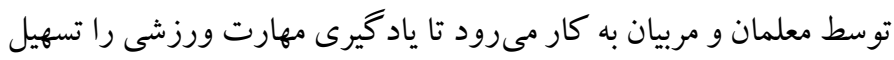

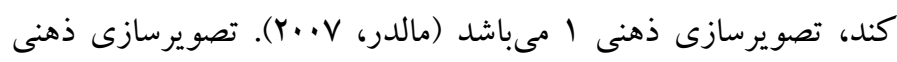

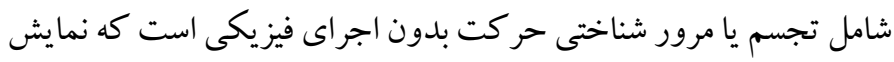

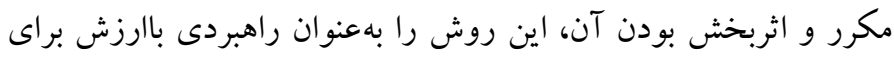

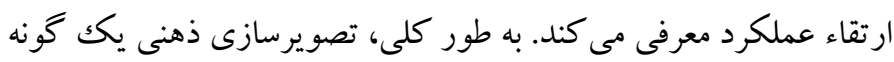

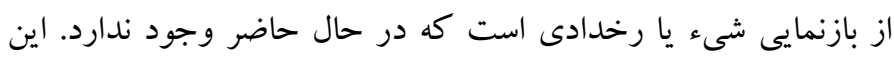

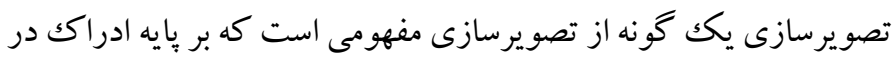

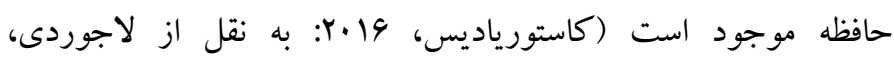
ميرزاحسينى و منيريور، لوجا1). اثرات تصويرسازى ذهنى بر اجرا بهطور

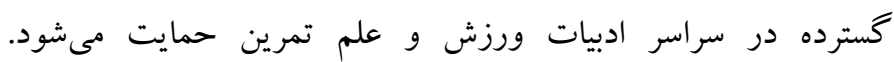

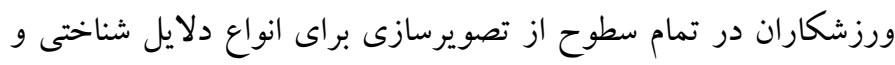

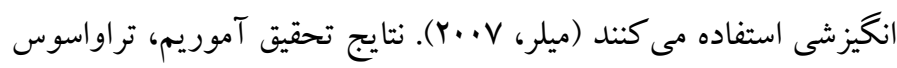
و ديورت (Y.IV) نشان داد نيازهاى ورزش مرتبط با توانايى هاى عملى، توانايى هاى مختلف تصويرسازى را براى آنها فراهم مى كند. در ادبيات

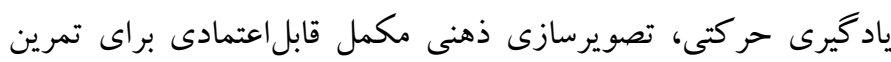

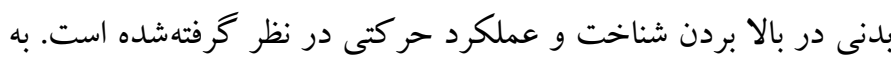
طورى كه تصور مفاهيم انتماعى را آسانتر مى سازد، مجموعهاى از

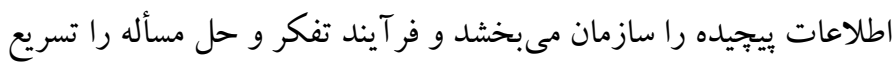

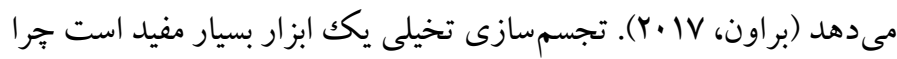

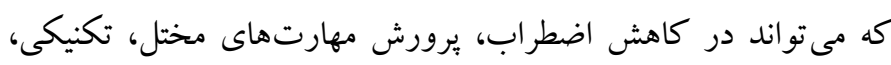

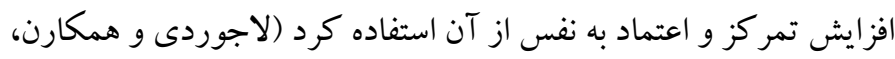
99rاן). با افزايش تصويرسازى ذهنى و ايجاد افكار مثبت در ورزشكار، كاهش اضطراب و اعتماد به خود وى را در حد مطلوب افزايش مى ده دهد

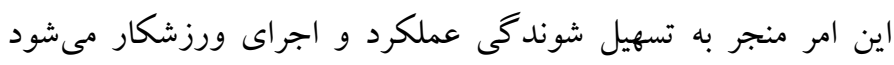

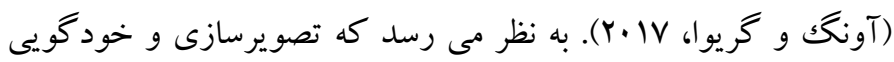
مثبت با تصور تصاوير و لحظات خوشايند و افكار منطقى و دورى از افكار

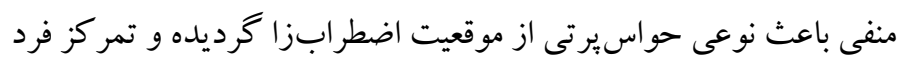




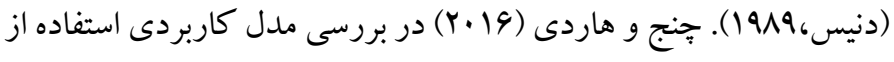

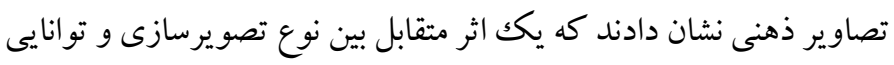

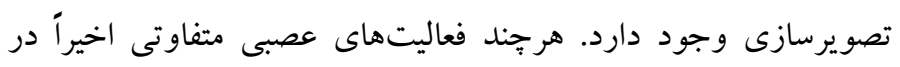
مطالعات تصويرسازى عصبى بررسى شده است و اين مطالعات نشان دادند

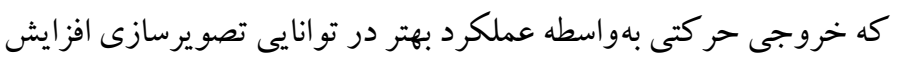

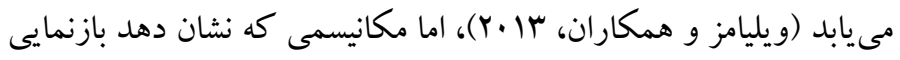
عصبى بهواسطه وضوح تصويرسازى باعث تأثيرات رفتارى متفاوت

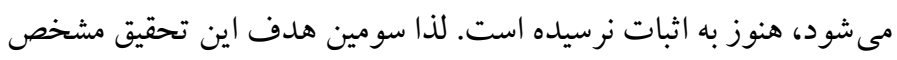
شدن تأثيرات وضوح تصويرسازى حر كتى روى به عملكرد حر كت مى بـ باشد.

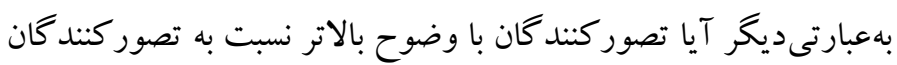
با وضوح بايين تر، در طى اجراى مهارت حر كتى بسته بهتر عمل مى كنند.

روش

الف) طرح يخؤش و شركت كنند كان: يزوهش از نوع شبهتجربى

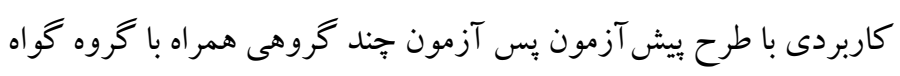

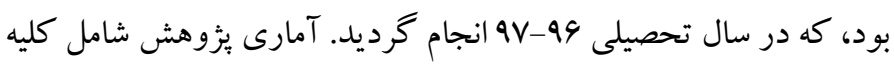
دانش آموزان دختر راست دست ^^تا • ا سال مقطع ابتدايى شهرستان اهواز

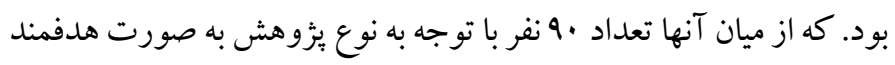

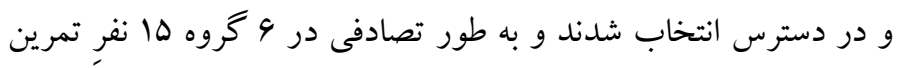
فيزيكى (PPG)، تصويرسازى ديدارى (VIG)' '(KIG) تركيب تمرين فيزيكى و تصويرسازى حركتى (VIPPG) و گروه كنترل (CG) همجنين سلامت كامل جسم و ذهن و اينكه در خذشته هر گز در معرض

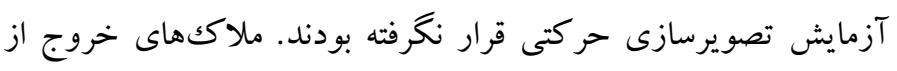

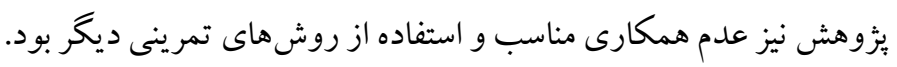

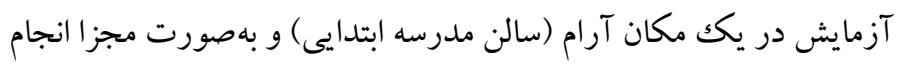
كرفت. به اين صورت كه هر يكك از آزمودنى ها با دست جِّ (دست غير

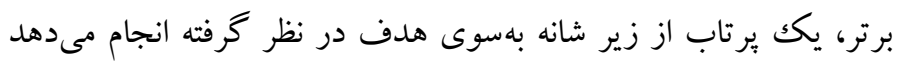

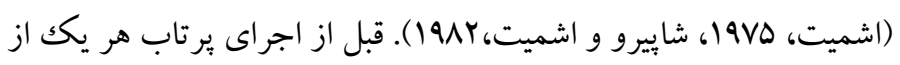

${ }^{3}$. visual imagery and physical practice composition 4 . control group
ديدارى مشخص كردند (فرى،ب..Y). درحالى كه فرم اوليه تصويرسازى،

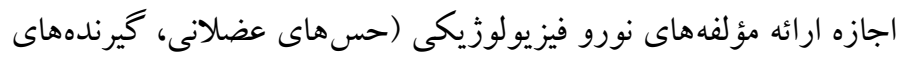

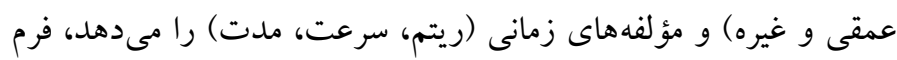
دوم اجازه فراخوانى مؤلفه هاى فضايى (به تصوير كشيده شدن فضا، اندازه،

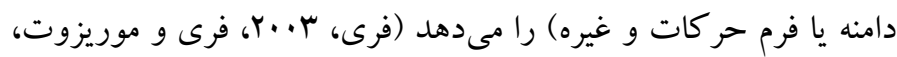
(Y...

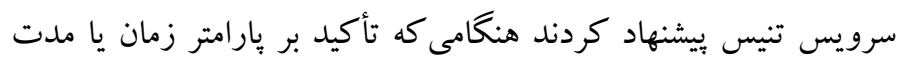

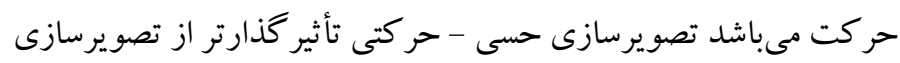

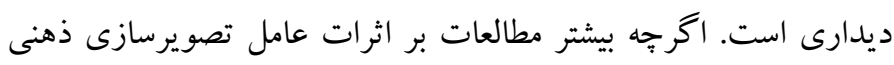

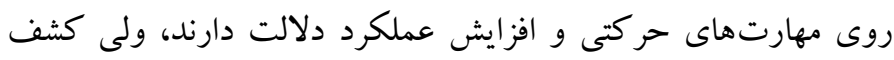
جنين نتايجى (تفاوت در تصويرسازى ديدارى و بينايى) در كودكان ودان

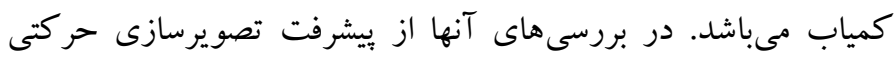

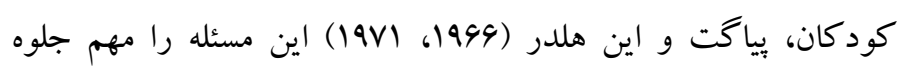

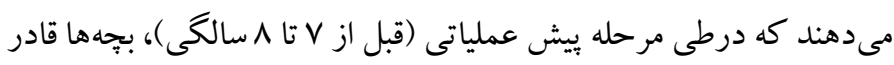

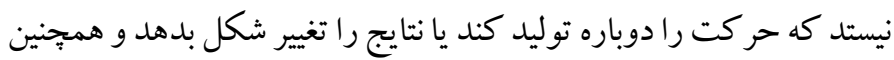

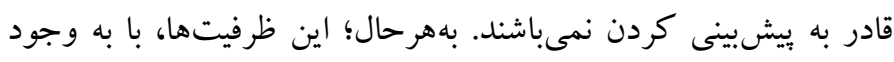

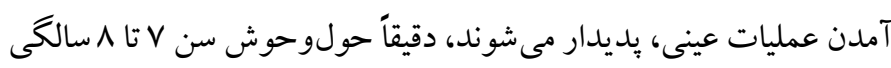

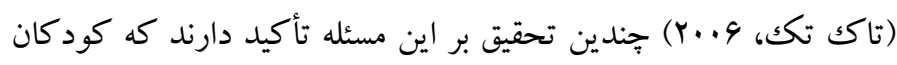

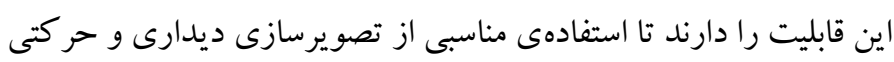

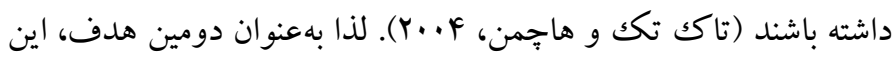
مسئله حائز اهميت بود كه كدام فرم از تصويرسازى ذهنى (ديدارى در مقابل حر كتى) بيشترين اثر را بر ياددارى و انتقال تكليف حر كتى بسته دارد.

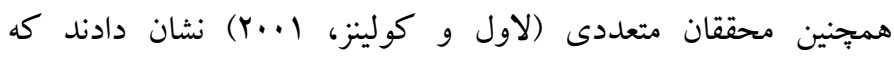

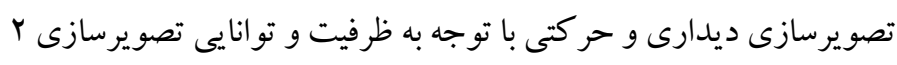

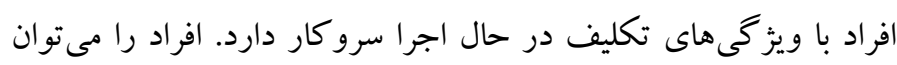

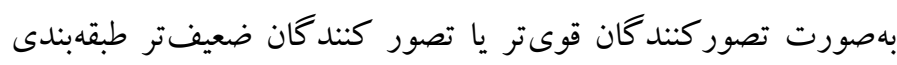

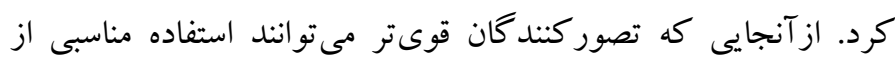

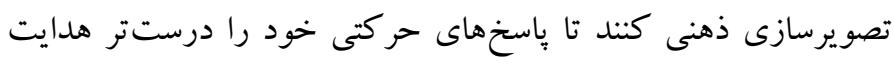
كنند، تصور كنند كان ضعيف تر سختى زيادى را در تكرار تصويرسازى

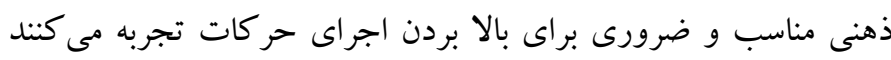

1. visual imagery group

${ }^{2}$. kinesthetic imagery and physical practice composition 


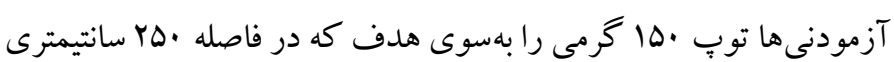

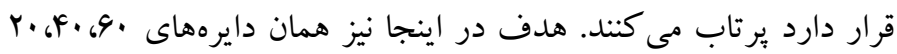

$$
\text { سانتيمترى مىباشند. }
$$

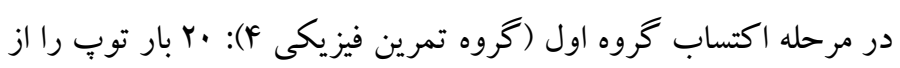
زير شانه به سمت هدف يرتاب مى كنند. گروه دوم (كروه تصويرسازى ديدارى ه): ·r بار توبّ تنيس را بهصورت ذهنى از زير شانه برتاب مى كنند با توجه به اين دستورعملها (توبٍ تنيس را با دست جٍِ نكهدار، جشمهايت را ببند، بهصورت خيلى روشنفكر كن كه توبٍ تنيس بهسوى مر كز هدف حركت مى كند در پايان حر كت جشمهايت را باز كن). كروه سوم (كروه تصويرسازى حر كتى 9): ·r بار توب تنيس رابهصورت ذهنى طبق اين دستور العمل هاى از زير شانه ير تاب مى كنند (توبِ تنيس رابا دست

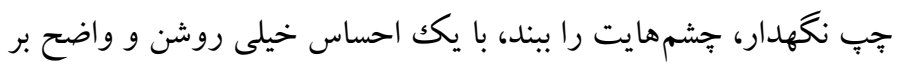

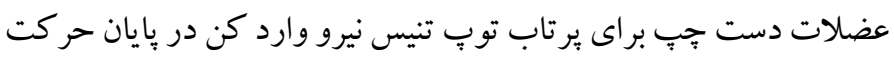
جشمهايت را باز كن) ). گروه جهارم (تر كيب تمرين فيزيكى و تصويرسازى ديدارى V): شركت كنند گان اين كروه · ا يرتاب را بهصورت فيزيكى همانند گروه اول انجام مىدهند و · إير تاب ديخر را بهصورت تصويرسازى ديدارى همانند گروه دوم انجام مىدهند. گروه ينجم (تركيب تمرين

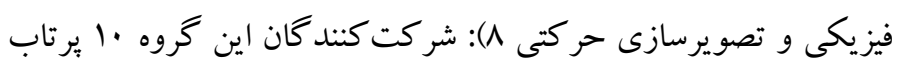
را بهصورت فيزيكى همانند كروه اول انجام مىدهند و · ا كوشش ير تابى ديخر را بهصورت تصويرسازى حركت همانند گروه سوم انجام مىدهند. كروه ششم (كروه كنترل 9): شر كت كنند كان اين گروه هيج گونه ير تابى را درى اين مرحله انجام نمى دهند. بدين ترتيب دادههاى مورد نياز جمع آورى شد؛ و در نهايت با استفاده از نرمافزار SPSS نسخه اب و آزمون تحليل واريانس مركب با اندازه كيرى تكرارى به تحليل يافته ها برداخته شد.

ب) ب ابز ار فرم مشخصات دمو گرافيك: براى جمع آورى اطلاعات جمعيت شناختى از يكك فرم كه دربر كيرنده r سؤال باز ياسخ (شامل سن و يايه تحصيلى) و Y سؤال بسته ياسخ (عدم شامل شر كت در فعاليت هاى تصويرسازى ذهنى در كذشته و عدم سلامت جسمى و ذهنى) بود، استفاده گرديد.
آزمودنىها از نحوهُ انجام حركت آكاهى ييدا كردند و دستورالعمل ها و آموزش هاى لازم مربوط به هر يكك از كروهها ارائه شد. ابتدا از آزمودنى خواسته مىشود كه بشت خط محدوده يرتاب، در فاصله Y مترى هدف

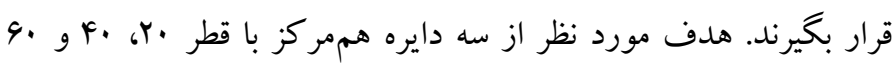
سانتيمترى تشكيل شده بود. اخر توبِ به دايره كو جّك (قطر ·r سانتىمتر) برخورد مى كرد ب امتياز اكر به دايره وسط (قطر م. سانتيمتر) برخورد مى كرد Y امتياز و اكر به دايره بزرك (قطر ·4 سانتيمتر) برخورد مى كرد يكك امتياز داده مىشد. ضمن اينكه مركز هدف (مركز دايرهها) در فاصله • سا سانتيمترى از ارتفاع زمين قرار دارد؛ كه اين هدف با يكك مداد. سياهروى قالب بزرگك كاغذ روى ديوار كشيده مىشود. شش هدف در فاصله ·. ․ سانتىمترى از فاصله اول تا ديخرى علامت گذارى شده بود (هر كدام به فاصله ·. . سانتى مترى از هم) بهطورى كه جندين شر كت كننده مىتوانستند يرتاب خود را بهطور همزمان بيندازند. آموزشها و و دستور العمل هاى تصوير سازى از قبل بهوسيله ضبطصوت آمادهشده بود. در

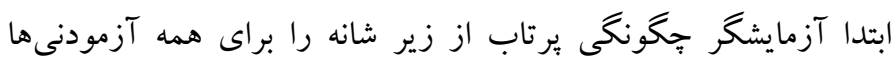
توضيح مىدهد و يككبار آن را اجرا مى كند بعدازاينكه تمام توضيحات داده شد و به سؤالات آزمونكرها نيز ياسخ داده شود و يسازاينكه تمام ابهامات و سؤالات درباره تكليف و جّكونگَى روش اجرا روشن شد مرحله بعدى كار شروع مىشود. قبل از شروع كار مربوط به هر گروه هر آزمودنى اجازه دارد ب بار برتاب از زير شانه را براى آشنا شدن با تكليف انجام دهد در حين اجرا آزمودنى ها يكك دوره · ا ثانيهاى بعد از هر ير تاب استراحت مى كنند و در طول اين · ا ثانيه بازخوردهاى لازم درباره تعداد امتياز و نتايج ير تاب به آزمودنى ها داده مى شود و براى برتاب بعدى آماده مى شود ضمن اينكه بعد از هر برتاب نتايج توسط آزمونگر ثبت مىشود. در ادامه براى رفع تأثيرات خستكى بعد ازهر بلوكك ينج كوششى (بعد از ه بار برتاب از زير شانه) يكك دوره · · ثانيهاى استراحت براى آزمودنىها در نظر كرفته شد. بهطور كلى هر آزمودنى ها برتاب را در V بلو كى ه تايى در مراحل مختلف ييش آزمون ه بار، اكتساب ·. بار، يس آزمون ه بار و انتقال هـ بار انجام داد. در مراحل ييش آزمون، تمرين و يس آزمون هر آزمودنى بيرتاب از زير شانه را با دست جِب و با يكك توب تنيس •ه گرمى به رنكَ زرد به سمت هدف كه در فاصله · ·. سانتيمترى قرار دارد يرتاب مى كند، هدف همان دايرههاى ·r، ·F، ·4 سانتيمترى هستند. ولى در مرحله انتقال همه 


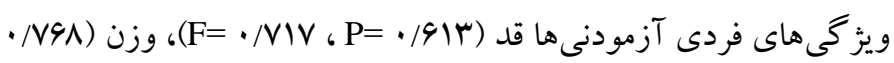

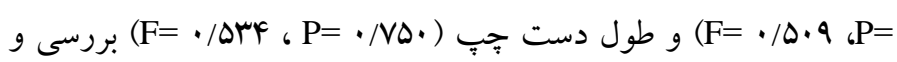
تأيد شد (ه •/ إ) و نتايج نشان داد اصل تفاوتهاى فردى در تحقيق حاضر كنترلشده است. همجنين از آنجايى كه روش آمارى بكار كرفته شده در اين تحقيق تحليل واريانس مختلط با اندازهيرى تكرارى مىباشد، مفروضه برابرى ماتريس كواريانس دادهها با توجه به عدم سطح معنىدارى آزمونهاى باكس (F= (D)

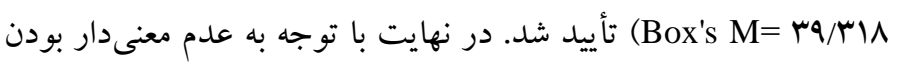
آزمون كرويت موخلى (Chi-Square= •/VF. dff= r، (Mauchly'sW= • • /991)، شاخص هاى (F) با در نظر گرفتن وجود اين

$$
\text { مفروضه گزارش شد. }
$$

ميانگين و انحر اف معيار امتيازات يرتاب از زير شانه در گروه هاى مختلف در مراحل ييش آزمون، يس آزمون و انتقال در جدول ا ارائه شده است. ابتدا جهت اطمينان از همسان بودن كروهها ازلحاظ امتيازهاى اجراى مهارت يرتاب زير شانه (عملكرد) و توانايى تصويرسازى در مرحله ييش آزمون از تحليل واريانس يككراهه استفاده شد كه نتايج نشان داد بين امتيازهاى اجراى مهارت يرتاب زير شانه (عملكرد) در گروههاى مختلف

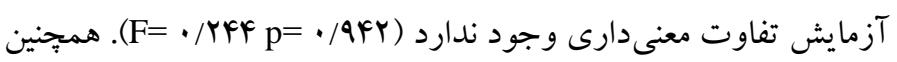
بين توانايى تصويرسازى در كروههاى مختلف آزمايش تفاوت معنىدارى

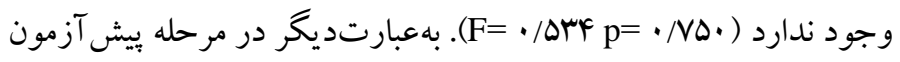
سطح عملكرد و توانايى تصويرسازى آزمودنىها در كروههاى مختلف برابر مىباشد. در ادامه جهت مقايسه عملكرد آزمودنىها در كروهها و مراحل مختلف آزمايشى از تحليل واريانس مركب با اندازه كيرى تكرارى (مرحله) ب× (كروه) و استفاده شد كه نتايج آن در جدول بار ارائه شده است.
يرسشنامه وضوح تصويرسازى حر كتى (VMIQ): اين يرسشنامه كه توانايى تصويرسازى حركت را مورد بررسى قرار مى دهد، نخستين بارتوسط ايساك، ماركز و راسل (1919) جهت بركردن خلا موجود در ادبيات مرتبط با تصويرسازى حركت ارائه شده است. اين برسشنامه FF سؤال با مقياس ه امتيازى ليكرت بود، اندازهكيرى شد. علاوه بر اينكه روايى صورى و محتوايى يرسشنامه توسط متخصصين و كارشناسان تربيتبدنى تأييد شد. بديعى (سوسا) روايى و يايايى برسشنامهٔوضوح تصويرسازى حركت را مورد بررسى قرار دادند و گزارش نمودند كه سؤالات يرسشنامه حدود FV درصد از كل واريانس مربوط به وضوح تصويرسازى حركت را شامل مى شود. براساس يافته هاى آنها مقدار ضرايب آلفاى كرونباخ براى خرده مقياس هاى تصويرسازى بصرى بيرونى، درونى و حر كتى و مقياس

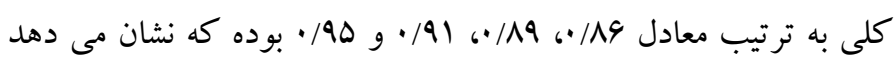
يايايى بالايى در اين خرده مقياسها و مقياس كلى وضوح تصويرسازى حركت وجود دارد. همجينين روايى سازه يرسشنامه با استفاده از روش

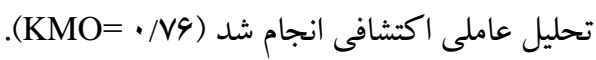

كافْته ها

در اين يثوهش •ه نفر از دانش آموزان مقطع ابتدايى با رنج سنى ^ تا . سال حضور داشتند. در ادامه به مقايسه ميانگين و تحليل آمارى يافتههاى يثوهشى برداخته مىشود. نرمال بودن و برابر بودن واريانسها از طريق

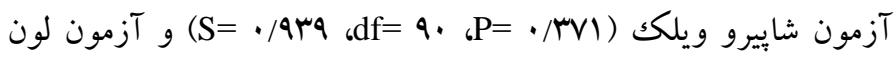

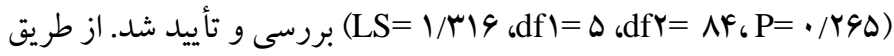
آزمون تحليل واريانس يككراهه همكنى گروهها يا به عبارتى برابرى

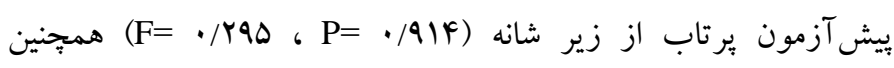

جدول ا. ميانكين و انحر اف معيار آزمودنى حها در اجراى يرتاب از زير شانه در هر كروه آزمايشى در مراحل مختلف آزمون

\begin{tabular}{|c|c|c|c|c|c|c|c|}
\hline \multicolumn{2}{|c|}{ انتقال } & \multicolumn{2}{|c|}{ بس آزمون (ياددارى) } & \multicolumn{2}{|c|}{ بيش آزمون } & \multirow{2}{*}{ 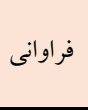 } & \multirow{2}{*}{ 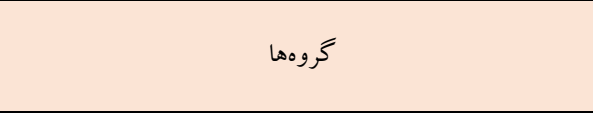 } \\
\hline انحر اف معيار & ميانگين & انحر اف معيار & ميانگين & انحراف معيار & 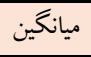 & & \\
\hline $1 / 94$ & $\mathrm{~V} / \cdot \cdot$ & $r / r$ & $1 \cdot \%$ & $r / \cdot r$ & V/F9 & 10 & كروه تمرين فيزيكى (PPG) \\
\hline$r / \Delta \Lambda$ & $9 / 9$. & $r / \mu r$ & $\Lambda / \wedge$. & r/FF & $V / 9$. & 10 & كروه تصويرسازى ديدارى (KIG) \\
\hline $1 / v$ & $\mathrm{~V} / \mathrm{V} r$ & $1 / 9 \Delta$ & $9 / \pi$ & $r / M$ & $9 / 94$ & 10 & كروه تصويرسازى حركتى (VIG) \\
\hline$r / 99$ & N/Dr & $r / \Delta r$ & $9 / 4$. & $r / \cdot r$ & $V / r q$ & 10 & كروه تركيب تصوير سازى ديدارى و تمرين فيزيكى (KIPPG) \\
\hline $1 / 94$ & $9 / .9$ & I/VD & $9 / 94$ & $1 / 91$ & $9 / 19$ & 10 & كروه تركيب تصويرسازى حركتى و تمرين فيزيكى (VIPPG) \\
\hline $1 / 91$ & $9 / 9$. & $1 / 91$ & $V / 9$. & r/YQ & $V / r q$ & 10 & گرووه كنترل (CG) \\
\hline
\end{tabular}


جدول r. يافتهحهاى تحليل واريانس مركب با اندازهحكيرى تكر ارى

\begin{tabular}{|c|c|c|c|c|c|c|}
\hline مجذور اتا & سطح معنى دارى & Fبت F F F F & ميانگين مجذورات & درجه آزادى & مجموع مجذورات & متغير \\
\hline.$/ 91 \mathrm{~F}$ &.$/ .1^{*}$ & $\Lambda / 19 V$ & $91 / A r$ & $r$ & $1 \wedge r / 90$ & مراحل \\
\hline וr// & $\cdot / \cdot V^{*}$ & r/DDG & N/Rr & 1. & & مراحل كروه \\
\hline.$/ .94$ & $\cdot / \mathrm{VV}$ & $1 / \Delta V$ & $11 / 94$ & $\Delta$ & $\Delta N / 19$ & گروه \\
\hline$=$ & $=$ & - & T/YD & 191 & $\Delta F V / I I$ & خطاى (مر احل) \\
\hline$=$ & $=$ & - & V/Ar & $\Delta F$ & GYI/VY & خطاى (گروه) \\
\hline
\end{tabular}

درونگ گروهى با اندازهگيرى تكرارى روى عامل مراحل نشان داد كه در

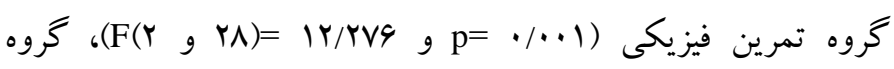
تصويرسازى ديدارى (

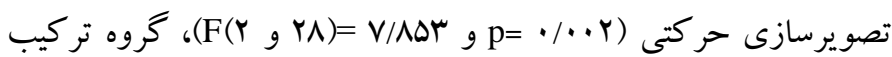

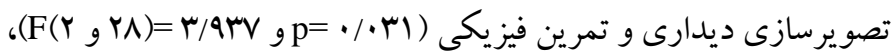

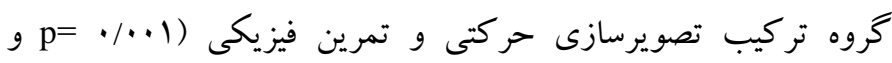

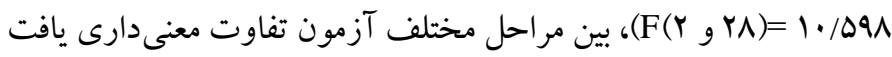
شد و و تفاوت معنىدارى مشاهده نشد. براى بررسى جايگاه تفاوتها از آزمون

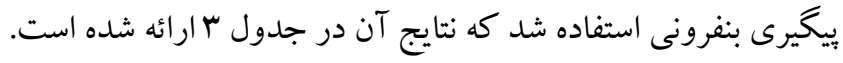

همانطور كه در جدول r مشاهده مىشود، يافتهاى مربوط به آزمون

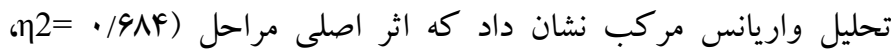

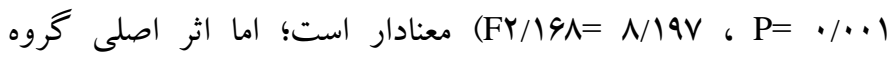

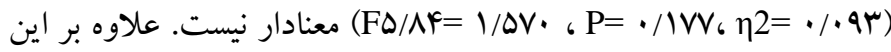
همانطور كه در جدول \& مشخص است تعامل مراحل و كروه

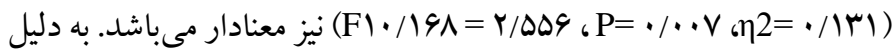
اينكه اثر تعاملى (مر احل ** گروه) معنادار است، از اثرات اصلى صرفنظر

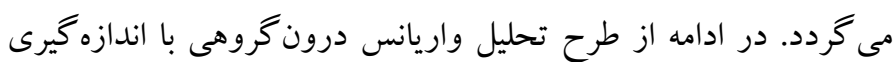

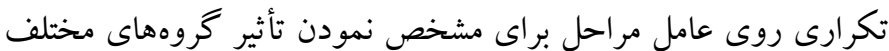

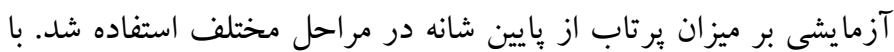

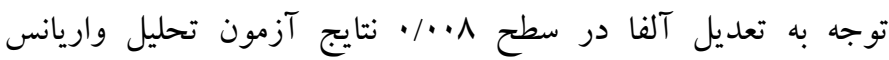

جدول لّ نتايج آزمون بيعيرى به روش بنفرونى براى بروسى جايغاه تفاوتها

\begin{tabular}{|c|c|c|c|c|c|}
\hline$P$ & 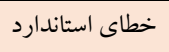 & j-i تفاوت ميانكينها & 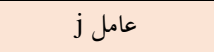 & عامل i ع & كروها إما \\
\hline $\begin{array}{l}* / \cdot \cdot F \\
\cdot / \Delta \cdot \Delta\end{array}$ & $\cdot / V Y$ &.$/ 49$ & يس (آزمون (ياددارى) & ي بيش آزمون & كروه تمرين فيزيكى (PPG) \\
\hline $\begin{array}{l}\cdot 1 \cdot \Delta 1 \\
. / T Y F\end{array}$ & $\cdot / \Delta 9$ & $\begin{array}{l}-1 / r \\
1 / \cdot\end{array}$ & 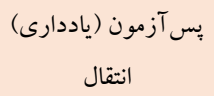 & ي ي بش آزمون & كروه تصوير سازى ديدارى (VIG) \\
\hline 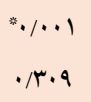 & $\cdot / \mathrm{rV}$ & $\begin{array}{l}-r / 4 . \\
-\cdot / A .\end{array}$ & 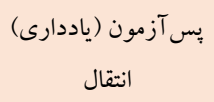 & ي ي بش آزمون & كروه تصويرسازى حر كتى (KIG) \\
\hline $\begin{array}{l}. / 104 \\
. / 1 \mathrm{rr}\end{array}$ & $\cdot / \mathrm{WV}$ & $\begin{array}{l}-Y / 1 Y \\
-1 / Y 4\end{array}$ & بـ آزمون (ياددارى) & ي ي بش آزمون & $\begin{array}{c}\text { كروه تركيب تصويرسازى ديدارى و تمرين } \\
\text { فيزيكى (VIPPG) }\end{array}$ \\
\hline$* / \cdots 1$ & $\begin{array}{l}\cdot / Y Y \\
\cdot / V Y\end{array}$ & $\begin{array}{l}-r / A \\
-r / r\end{array}$ & 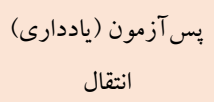 & ي ي بش آزمون & 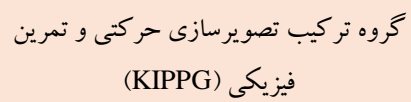 \\
\hline$\cdot / 0 \cdot 4$ & $\cdot / 4 A$ & $\begin{array}{l}-\cdot / 44 \\
.199\end{array}$ & 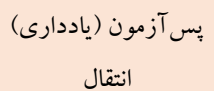 & ي يش آزمون & كروه كنترل (CG) \\
\hline
\end{tabular}

KIG, SPPG

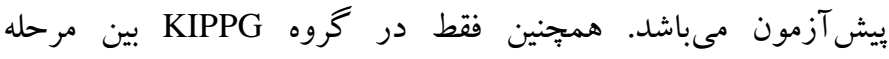
ييش آزمون و انتقال تفاوت معنىدارى يافت شد. بهطورى كه تعداد
همانطور كه در جدول ץ مشاهده مىشود، در همه گروههاى آزمايشى

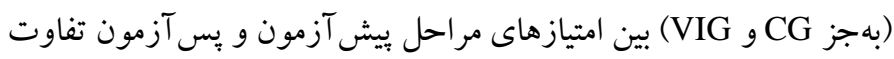
VIPPG, KIPPG, معنى 


\section{بحث و نتيجله تيرى}

هدف از يزوهش حاضر تأثير انواع مختلف تصويرسازى ذهنى ديدارى و

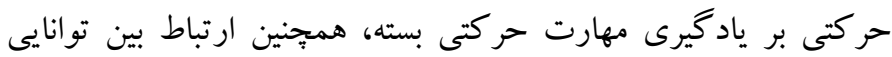

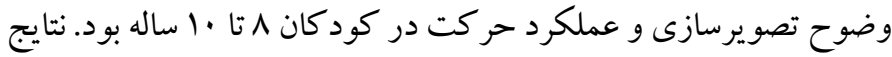
تحقيق نشان داد كه در مرحله بيش آزمون سطح عملكرد و توانايى

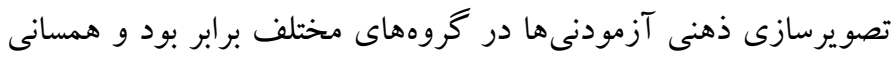
اوليه سطح مهارت حركتى و توانايى تصويرسازى ذهنى آزمودنىها تأييد

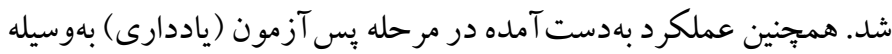
خروههاى تصويرسازى (VIG,KIG,VIPPG,KIPPG) با آنجه در گرووه تمرين فيزيكى (PPG) به دست آمد برابر بود، اين برابرى نشاندهنده اثربخش بودن تصويرسازى ذهنى بر عملكرد مهارتهاى حر كتى مى باشد

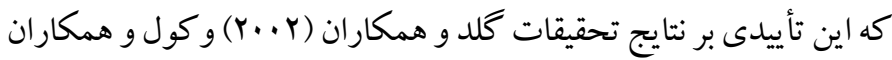
(1997) مىباشد. در اين زمينه بديعى نامقى (سوس|) نيز نشان داد هر دو

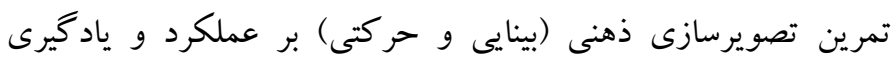
سرويس كوتاه بدمينتون مؤثر است. در رابطه با اثربخشى تصويرسازى ذهنى بر بهبود عملكرد حر كتى مى توان به دو گروه از تبيينهاى شناختى و

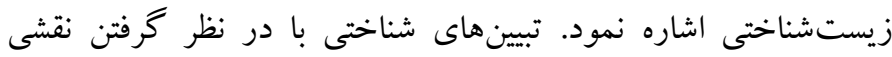

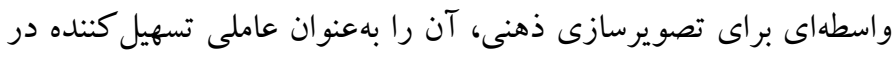

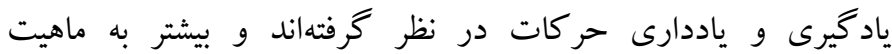
تصويرسازى و فرآيندهاى حافظهاى دخيل در آن مىيردازند (موران،

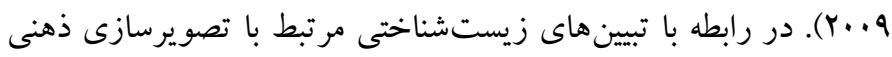

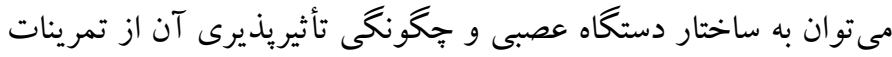

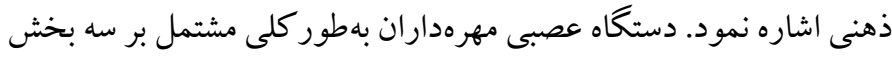

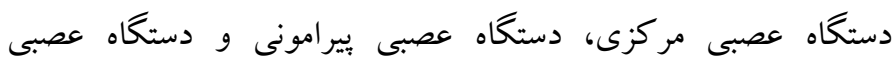
خودمختار مىباشد (خدايناهى، هوبا). كنترل فعاليتهاى حركتى از طريق مناطق مختلف سيستم عصبى صورت مى گيرد. ياد گيرى مهارتهاى

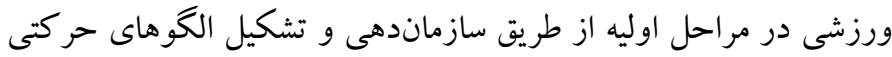

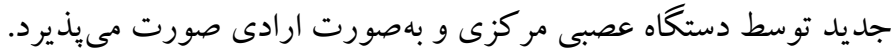

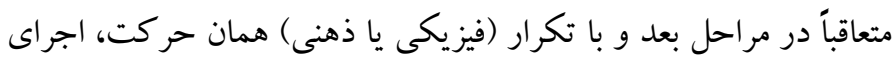
حركت بدون نياز به توجه هشيار و توسط سيستم خودمختار صورت

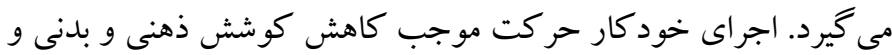

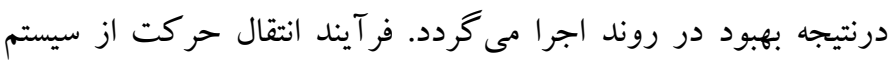

امتيازهاى KIPPG در مرحله انتقال بهطور معنىدارى بالاتر از مرحله بيش آزمون مىباشد. ولى در ديخر خروهها بين مرحله بيش آزمون و و انتقال تفاوت معنى دارى يافت نشد. بعد از بررسى تفاوتهاى درون گروهى، با توجه به معنى دارى تعامل مر احل يل

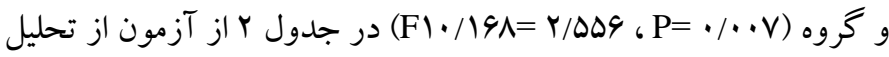
واريانس يككراهه (ANOVA) جهت بررسى تفاوتهاى بين گروهى در

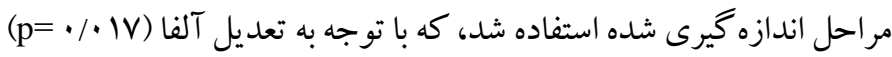

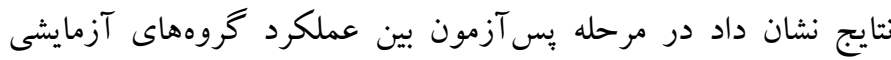

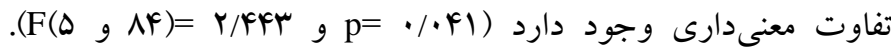
بهورى كه نتايج آزمون بيخردى توكى نشان داد عملكرد همه كروهوداى آزمايشى (VIPPG, KIPPG, KIG, SPPG) بهطور معنىدارى بالاتر از

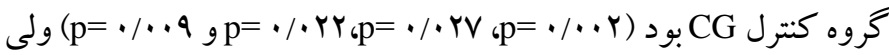
بين عملكرد گروه VIG با گروه CG تفاوت معنىدارى يافت نشد. ضمن

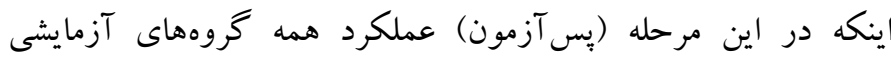
(VIPPG, KIPPG, KIG, VIG, SPPG) مرحله انتقال بين عملكرد گروههاى آزمايشى تفاوت معنى دارى وجود دارد

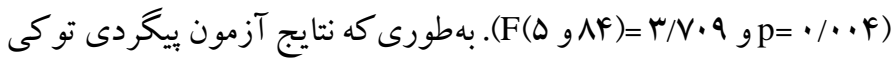
نشان داد عملكرد كروههاى آزمايشى (VIPPG, KIPPG) بهطور معنى

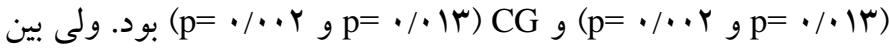
عملكرد گرووهاى آزمايشى (VIPPG, KIPPG) با KIG تفاوت معنى دارى يافت نشد، ضمن اينكه بين ديخر گرووهاى آزمايش تفاوت معنىدارى يافت نشد. جهت ارتباط بين توانايى تصويرسازى ذهنى و عملكرد حر كتى در مراحل

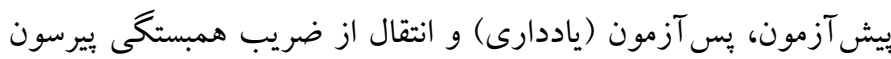
استفاده شد؛ كه نتايج نشان داد بين توانايى تصويرسازى ذهنى با عملكرد

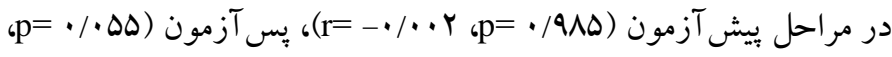

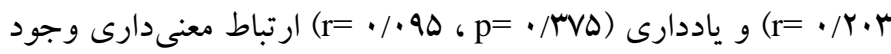


مكانيزم مشترك را با هم استفاده مى كنند كه سازماندهى موقت حر كات

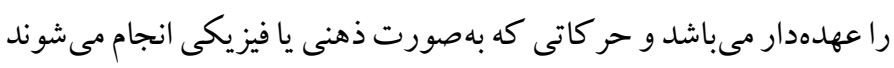
از طريق يكك برنامه حر كتى عمومى يكسان كنترل مى شوند (دستى

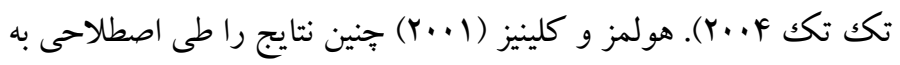
نام "سند رفتارى براى برابرى عملكرد" بين تصويرسازى ذهنى و تمرين

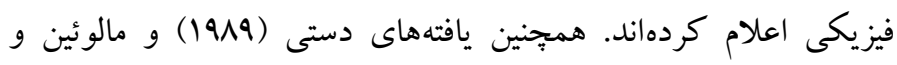
همكاران (Y...T) اظهار كردند كه تصويرسازى ذهنى و تمرين فيزيكى،

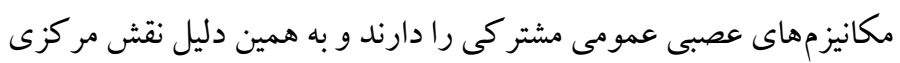
برابرى در اجراى تكاليف حر كتى ايفا مى كنند. (هولمز و كولينز، (ب. (Y).

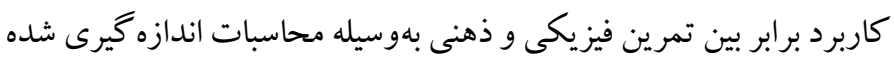

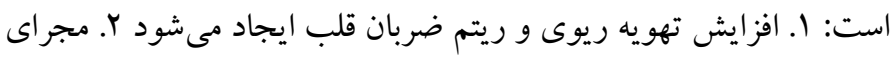
قلبى -عروقى و تنفسى در طى ارتعاش تغيير مى كنند و سا. همزمان با افزايش تلاش جهت تصويرسازى فر كانس قلبى و تهويه افزايش مى يابد (بوليت و

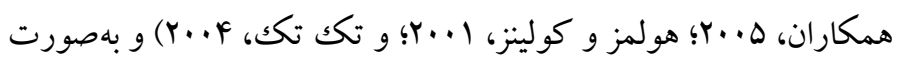
دقيق تر ديجومز - مولينارو و همكاران (1991) سه نمونه از شرايط دوره

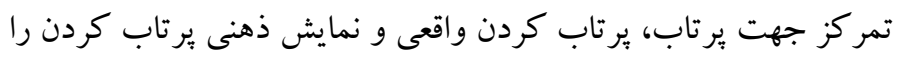
مقايسه كردهاند. در اين تحقيق شش متغير سيستم عصبى مركزى (يتانسيل يوست، مقاومت بوست، جريان خون بوست، دماى بوست، سرعت آنى

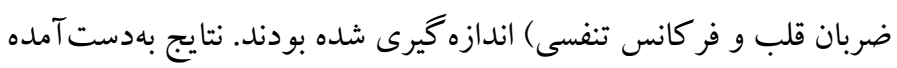

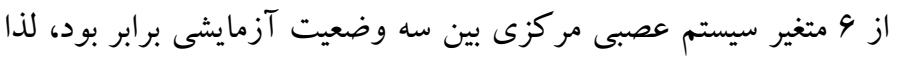

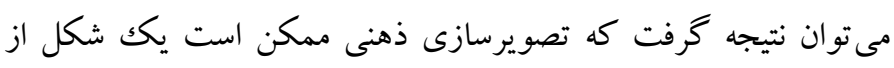

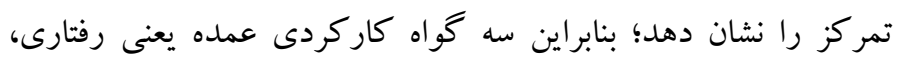
مركزى و يير امونى را مى توان دليل برابرى عملكرد به دست آمده در مر حله

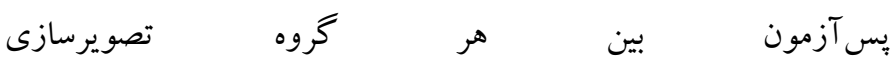
در تحقيق حاضر بيان كرد (هولمز (SPPG,VIG,KIG,VIPPG,KIPPG)

$$
\text { و كولينز، (r. (r). }
$$

نتايج بهدست آمده در مرحله انتقال نشان داد كه تر كيب تصويرسازى ذهنى با تمرين فيزيكى (KIPPG,VIPPG) بهطور قابل ملاحظهاى عملكرد

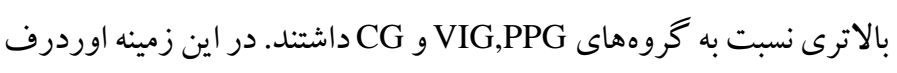
نيز در تحقيق خود نشان داد تركيب تمرين ذهنى و بلدنى مى تواند (Y...F) مؤثرتر از تمرين فيزيكى يا تمرين ذهنى بهطور مجزا باشد. اين نتايج را

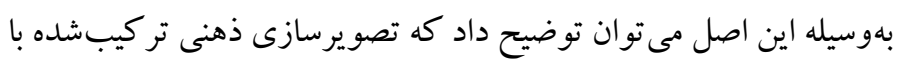

عصبى مر كزى به سيستم خود كار و درنتيجه اجراى عالى عملكرد حر كتى، بهواسطهى تمرينات فيزيكى و يا ذهنى ايجاد مى شود. تصويرسازى ذهنى

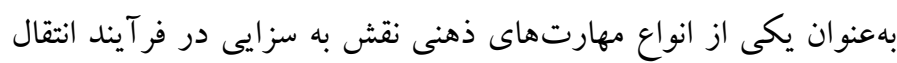

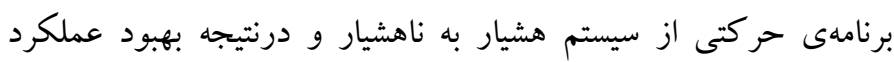
حر كتى بر عهده دارد (كانيس و همكاران، F +..r).

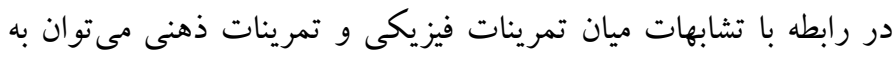

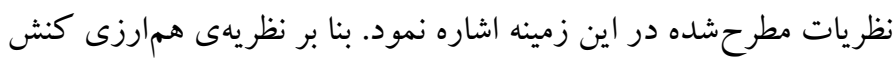

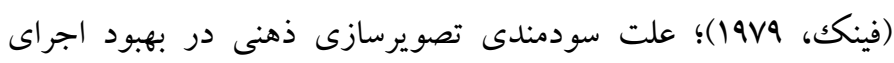
عملكرد حركتى، به هميوشانى مراكز مغزى مربوط به تصويرسازى و

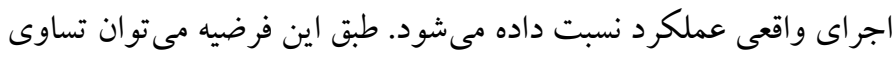
مدتزمان صرف شده براى تصور و اجراى واقعى حركت را بر مبناى

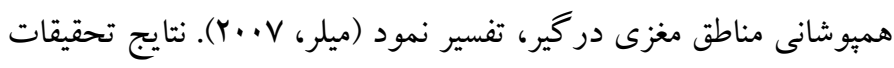

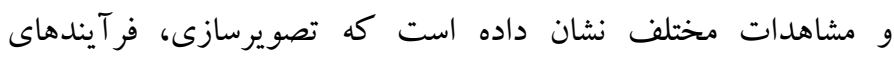
طرحريزى و آمادگى حركت را بيش از فر آيندهاى اجر ايى فعال مى كند.

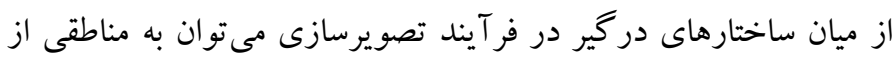

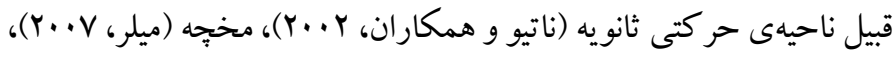

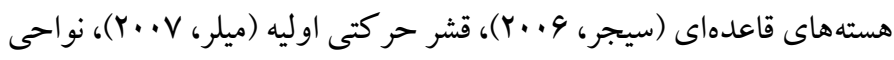

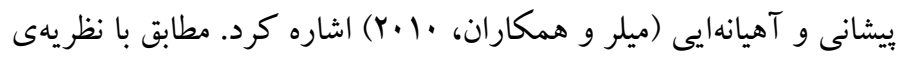

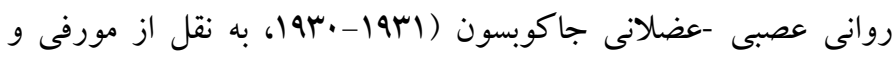

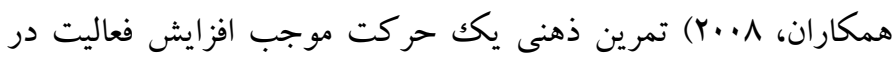
عضلات مرتبط با اجراى واقعى آن حركت مىشود؛ اما با توجه به اين امر

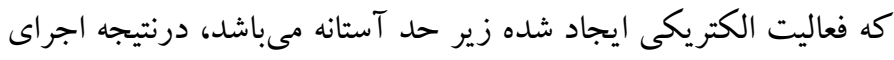

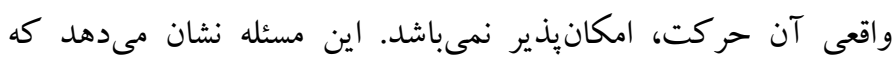
تصويرسازى (خصوصاً تصويرسازى ذهنى داخلى) منجر به فعالسازى راههاى عصبى مورد استفاده در اجراى واقعى مهارت مىشود و يا به بيانى

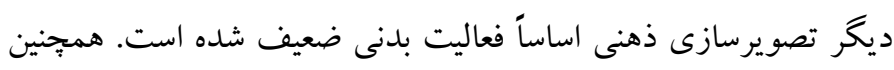

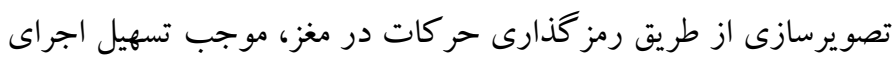

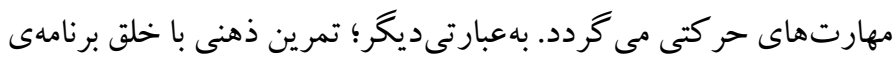

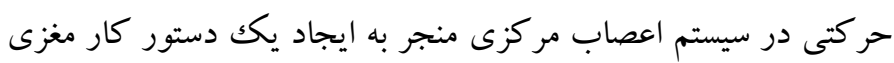
جهت اجراى صحيح حر كات مىشود (مورفى، نوردينگك و كامينگك،

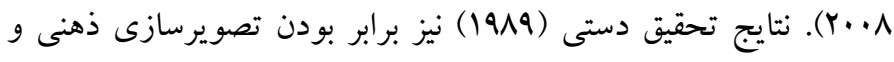

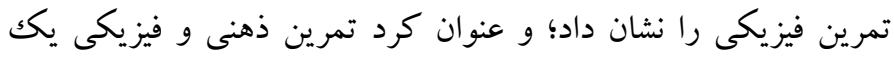


عملكرد بهدست آمده در هر گروه تركيبى تصويرسازى با تمرين فيزيكى يا VIPPG)

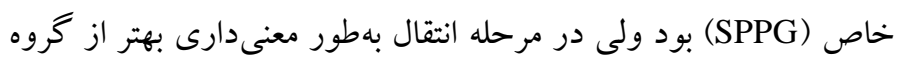

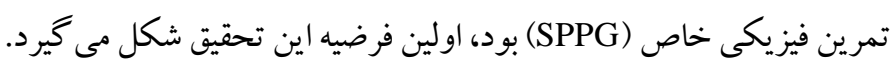
لذا با توجه به نتايج تحقيق، مىتوان از تصويرسازى ذهنى جهت بهبود

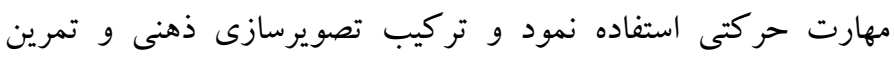
جسمانى در مقايسه با تمرين جسمانى صرف، اثربخشى بيشترى بر عملكرد حر كتى خواهد داشت.

نتايج اين تحقيق همجنان نشان مىدهد كه گروههاى تصويرسازى ذهنى

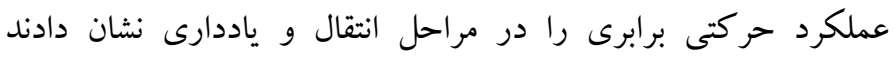

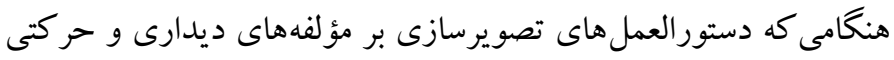
تأكيد داشته باشند (KIG=VIG و مIPPG=VIPPG). در اين زمينه نتايج تحقيق بديعى نامقى (سوس|) نشان داد كه تصويرسازى بينايى باعث ياد گيرى بهتر سرويس كوتاه بدمينتون نسبت به تصويرسازى حر كتى در

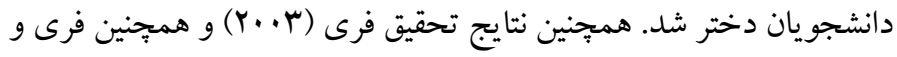

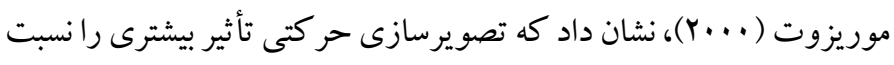
به تصويرسازى ديدارى دارد هنگامى كه در طى حركت بارامتر زمانى يا

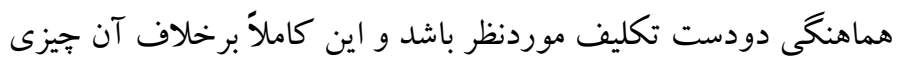

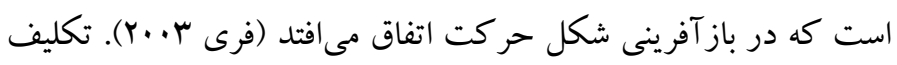
آزمايشى به كاربرده شده در اين تحقيق موجب هماهنكى حر كتى يكدست

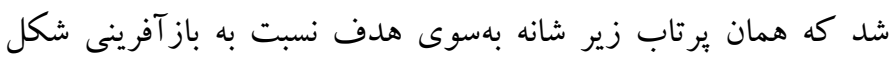

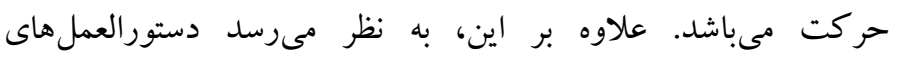

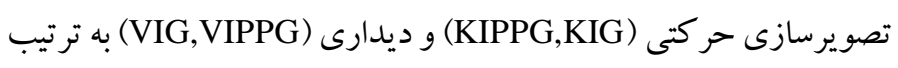
تأكيد بر نيروى موردنياز جهت برتاب توب (بهوضوح احساس مى شود كه ونه

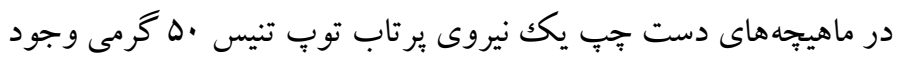

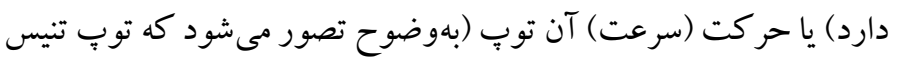
به سمت مركز هدف واقع در . . سانتىمترى حركت مى كند) دارند؛ بنابراين، برابرى عملكرد بهدست آمده بين دستورالعملهاى تصويرسازى

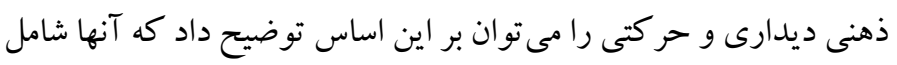
بارامترهاى شبيه به هم تكليف حركتى هستند كه اين دستور العمل ها بر

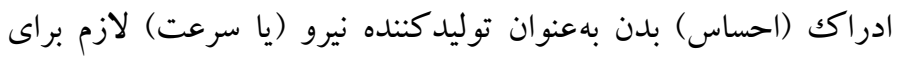

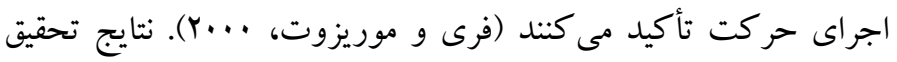

كروه تمرين فيزيكى (KIPPG,VIPPG) به آزمودنىها اجازه داد تا در طى مرحله اكتساب تمرين كنند. درواقع دو استراتزى يادگيرى حركتى

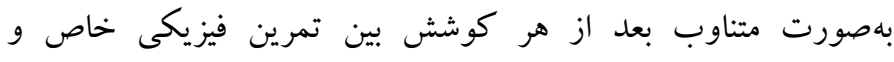

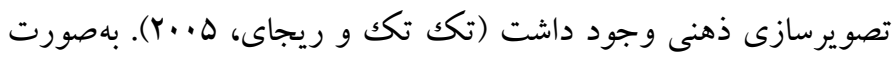

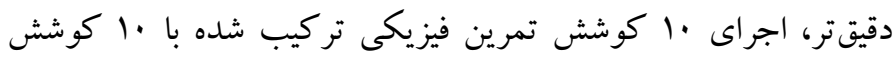

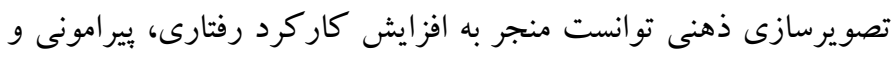

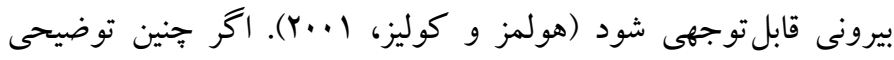

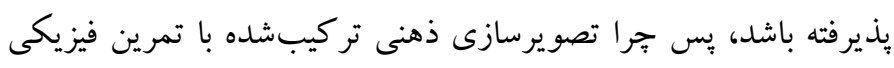

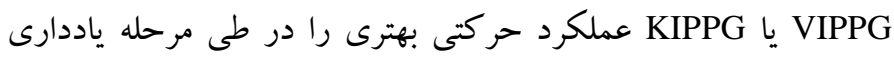

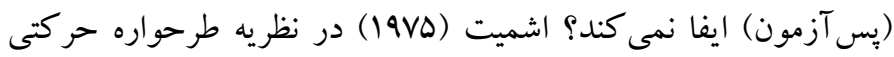
خود فرض مى كند كه در طى مرحله اكتساب، تمرين متغير در مقايسه با تهاب

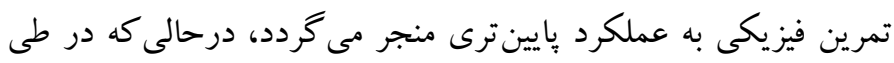

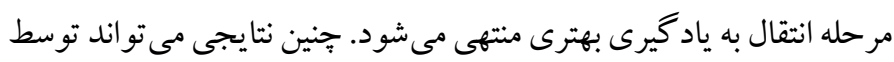
اين حقيقت توضيح داده شود كه تمرين متغير به طرحواره حركتى قابل

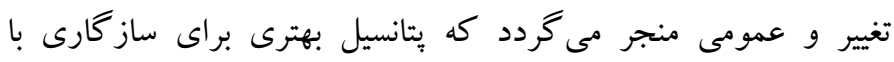
مهارتهاى حر كتى جديد را دارد و بسيار شبيه، نه يكسان، به تكليف انتقال است. احتمالاً اين حقيقت در مورد تركيب تصويرسازى ذهنى و تمرين

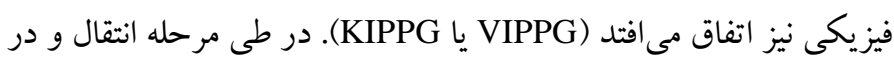

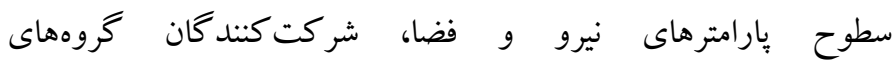
KIPPG,VIPPG قابل تغيير بيردازند تا اين تغييرات در سر تاسر مرحله ادامه داشته باشد. هرجند كه اين مورد شامل گروههاى PPG, CG نبود. به نظر مىرسد كه ياد گيرى تيرى

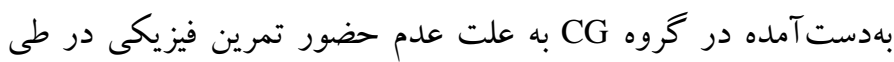

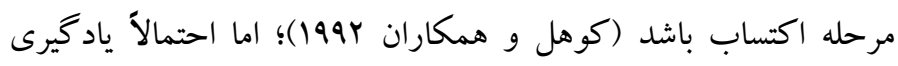

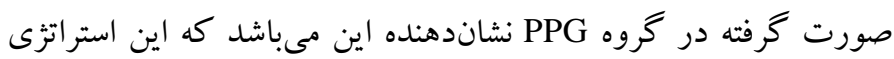
تمرينى براى تحكيم بارامترهاى نيرو و فضايى طرحواره حركتى معقولانه

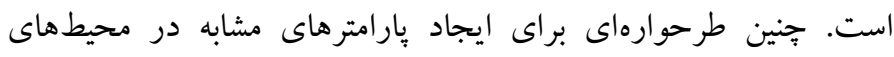

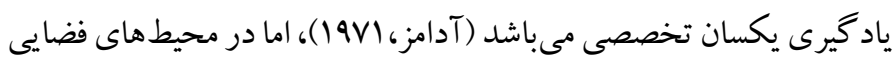

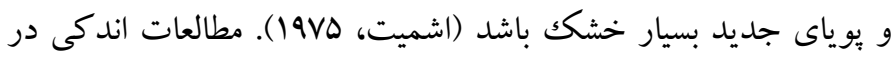

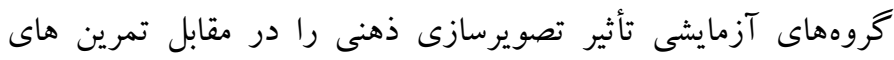
فيزيكى بر اجرا و يادگيرى مهارت هاى حر كتى بررسى كرده اند (اشميت،

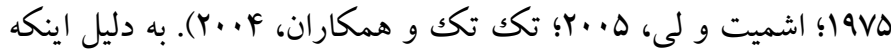


مىدهد كه احتمالاً اين تكليف آزمايشى بر توانايى تصويرسازى ذهنى

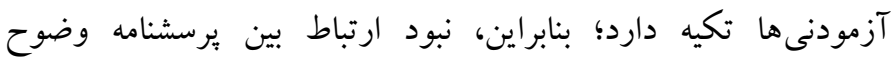

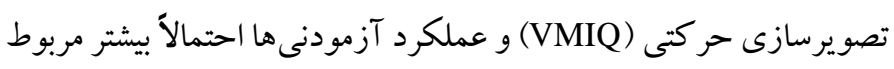

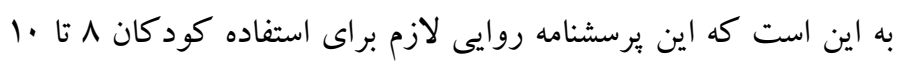

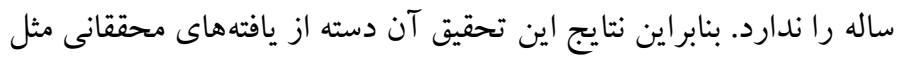

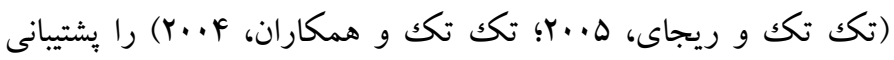

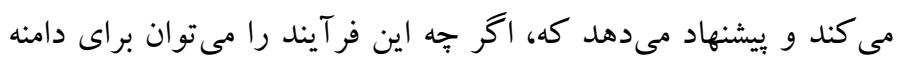

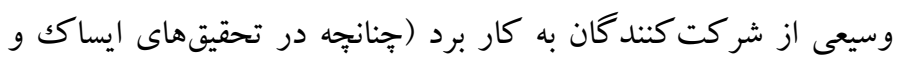

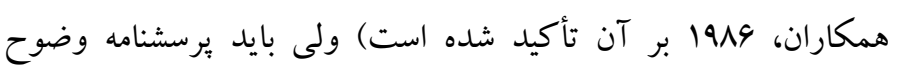

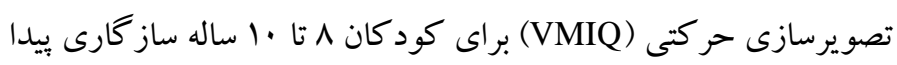

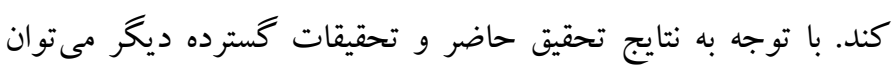

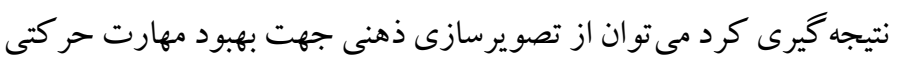

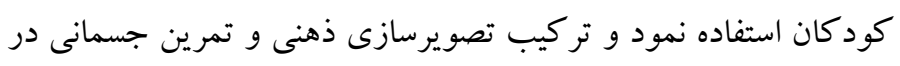
مقايسه با تمرين جسمانى صرف، اثربخشى بيشترى بر عملكرد حركتى

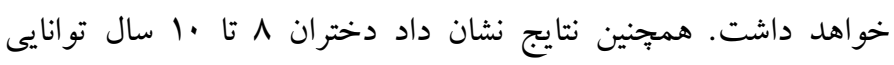

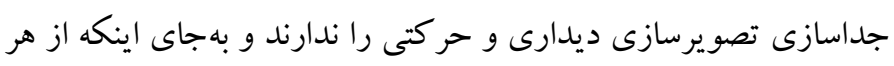

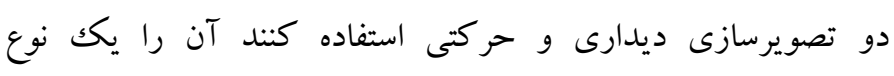
تصويرسازى قلمداد كرده بودند. لذا بيشنهاد مى شود اين تحقيق در سنين

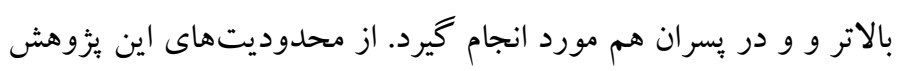

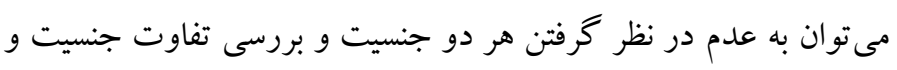
همجنين عدم توجه به تا خر و تقدم در مداخله گُروه تر كيبى اشاره كرد.

ملاحضات اخلاقى (احق بيروى از اصول اخلاق ثزوهش: اين مقاله بركرفته از يزوهش انجام خرفته در دوره فرصت مطالعاتى يزوهشكاه تربيت بدنى مى إشافد.

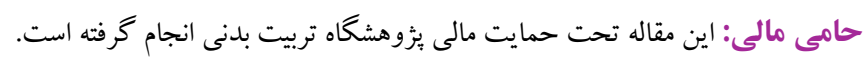

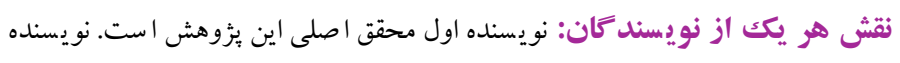

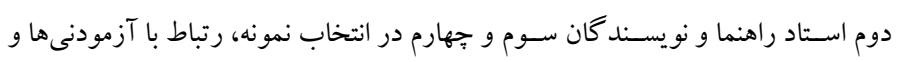
جمع آورى دادهها كمكك كننده بودهاند.

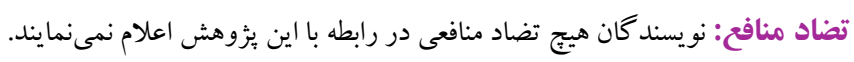

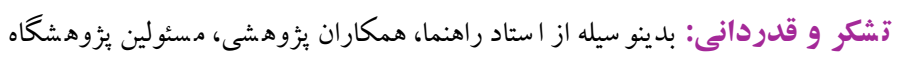

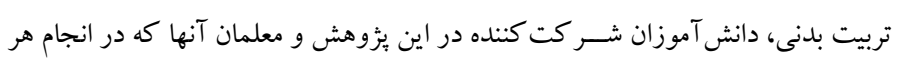
جه بهتر اين يثوهش ما را يارى نمودند كمال تشكر و قدردانى راد دارم.

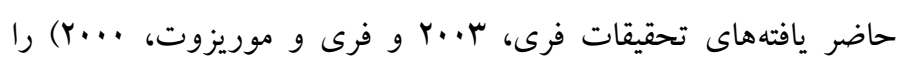
يشتيبانى مى كند. عدم موفقيت در ويدا كردن هر تفاوتى بين شرايط

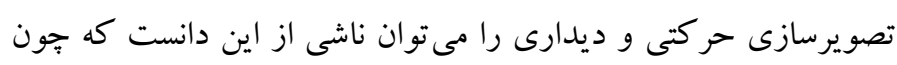

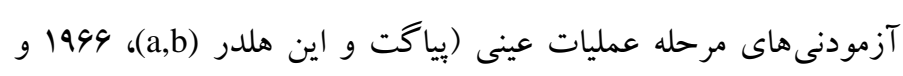

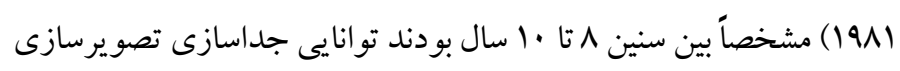

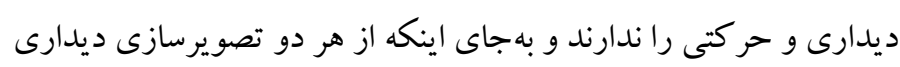

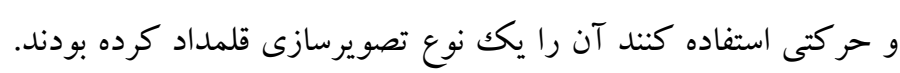

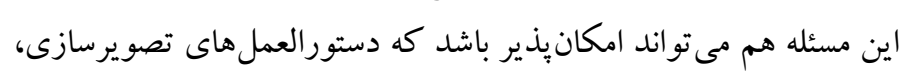

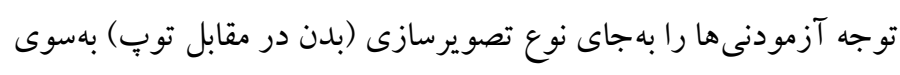

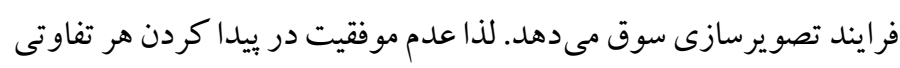
بين شرايط تصويرسازى حركتى و ديدارى نشان از عدم تأييد فرضيه دوم تحقيق مىباشد.

نتايج تحقيق هيج گونه ارتباط مثبتى را بين امتياز آزمودنى ها در برسشنامه وضوح تصويرسازى حر كتى (VMIQ) و عملكرد حر كتى آنها در مر احل

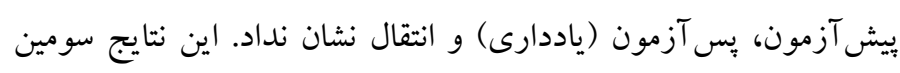
فرضيه اين تحقيق را رد كرد. در اين فرضيه بيان شد كه تصوير كنند أنان قوى تر در طى اجراى يكك مهارت حر كتى بسته بهتر از تصور كنند أنان

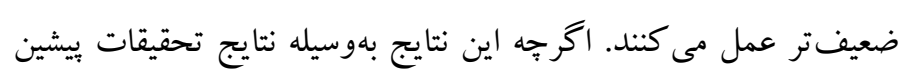

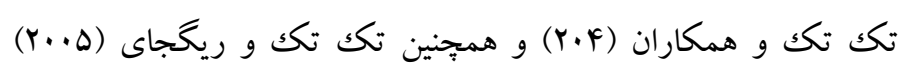

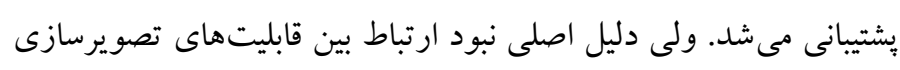

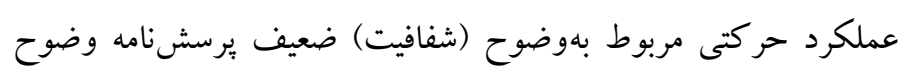
تصويرسازى حر كتى (VMIQ) مى باشد. اين دليل را مى توان به احساسات

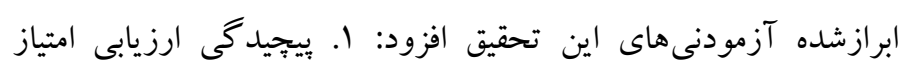

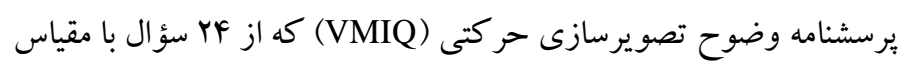
ينج امتيازى ليكرت در هر ديدكاه تصويرسازى (درونى و بيرونى) تشكيلشده بود. r. مدتزمان طولانى در بررسى يرسشنامه كه عامل

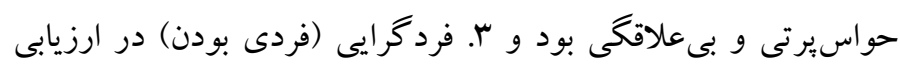
شفافيت و وضوح تصوير سازى ذهنى مناسب حر كت در ياسخ به به سؤ ال. تكليف آزمايش مطالعه حاضر (برتاب از زير شانه) همانند معيارهاى

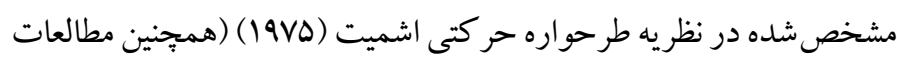

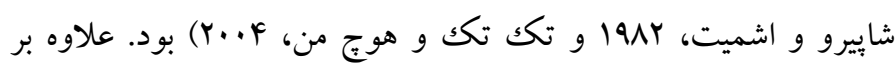
يبشرفت عملكرد از مرحله بيش آزمون تا مرحله بِ آزمون و انتقال نشان 


\section{References}

Abma C L, Fry M. D, Li Y, Relyea G. (2002). Differences in imagery content and imagery ability between high and low confident track and field athletes. Journal of Applied Sport Psychology, 14 (2). 67-75. [Link]

Amorim, A. P., Travassos, B., Duarte-Mende, P. (2017). Imagery ability in Boccia: Comparison among federate athletes from different medical sport groups. Journal Motricidade, 13(4). 46-53. [Link]

Bolliet, O., Collet, C., Dittmar, A. (2005). Autonomie nervous system activity during actual and mentally simulated preparation for movement. Applied Psychophysiology and Biofeedback, 30. 11-20. [Link]

Brown, R. (2017). Art and science in the romanticism agination: creativity assumes a variety of naturalyet imaginary, forms in these painstakingly carvedpaper sculptures. American Scientist.105 (2). 82-86. [Link]

Castoriadis, C. (2016). Radical imagination and the socialinstituting imaginary. In Rethinking Imagination. 136-154. Routledge. [Link]

Cheng, W. N. K., Hardy, L. (2016). Three-dimensional model of performance anxiety: Tests of the adaptivepotential of the regulatory dimension of anxiety. Psychology of Sport and Exercise, 22. 255263. [Link]

Decety, J. (1989). Simulation mentale du mouvement: Approche neurocognitive. Analyse chronométrique d'actions exécutées mentalement et étude du métabolisme cérébral par mesure du débit sanguin cérébral régional. [Mental stimulation of movement: Neurocognitive approach. Chronometrie analysts of mental executed actions and study of the cerebral metabolism by measurement of the regional cerebral blood flow. Unpublished doctoral dissertation, Université Claude Bernard. [Link]

Denis, M. (1989). Image et cognition. [Image and cognition.] Paris: Presses Universitaires de France.

Deschaumes-Molinaro, C., Dittmar, A., Vernet-Maury, E. (1991). Relationship between mental imagery and sporting performance. Behavioral Brain Research, 45. 29-36. [Link]

Féry, Y.-A. (2003). Differentiating visual and kinesthetic imagery in mental practice. Canadian Journal of Experimental Psychology, 57.1-10. [Link]

Féry, Y.-A., Morizot, P. (2000). Kinesthetic and visual image in modeling closed motor skills: The example of the tennis serve. Perceptual and Motor Skills, 90(3, PtI). 707-722. [Link]

Ganis, G, Thompson, W. L, Kosslyn, S. M. (2004). Brain areas underlying visual mental imagery and visual perception: an fMRI study. Journal of cognitive brain research, (20). 226-241. [Link]

Gharaiagh Z., H.; Honarmand, P.; Rahimzadeh, M.; Abdullahzadeh, S. \& Amouzadeh, F. (2019). The effect of psychological skill training on competitive anxiety and self-confidence in student athletes. Psychological Sciences, 18 (84). 2264-2257. (Persian). [Link]

Glyn C, Coen. (2000). Learning experiences in sport psychology. Translated: Vaez Mosavi M K, Shojaee M. first published Tehran: Publications Development, 123-5. [Link]

Gould, D., Damarjian, N., Greenleaf, C. (2002). Imagery training for peak performance. In J. L. Van Raalte (Ed.). Exploring sport and exercise psychology (2nd éd. pp: 49-74). Washington, DC: American Psychological Association. [Link]

Hamzeh, Kh; Nawabinejad, Sh. Shafiabadi, A. (2015 Comparison of Schema Therapy, Applied Relaxation and Mental Imagery Effectiveness to Reduce Cognitive State Anxiety of Elite Athletes.Sports Psychology Studies, 5 (18). 99-114. (Persian). [Link]

Holmes, P. S., Collins, D. J. (2001). The PETTLEP to motor imagery: A functional equivalence model for sport psychologists. Journal of Applied Sport Psychology, 13, PP: 60-83. [Link]

Isaac, A., Marks, D. F., Russell, D. G. (1986). An instrument for assessing imagery of movement: The Vividness of Movement Imagery Questionnaire (VMIQ). Journal of Mental Imagery, 70(4), 23-30. [Link]

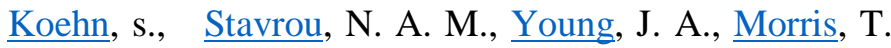
(2015). The applied model of imagery use: Examination of moderation and mediation effects Scand J Med Sci Sports.. 26(8), 975-84. [Link]

Kohl, R. M., Ellis, S. D., Roenker, D. L. (1992). Alternating actual and imagery practice: Preliminary theoretical considerations. Research Quarterly for Exercise and Sport, 63, 162-170. [Link]

Lajevardi, H.; Mirza Hosseini, H. Monirpour, (2018). A Comparative Study of Three Methods`Activation of Mental visualization, Imaginary Visualization and Presentation of Images in the Activation of the Abandonment Schema in People with Borderline 
Personality Disorder,Journal of Psychological Science, 17 (71), 817-821. (Persian). [Link]

Lajevardi, H.; Mirza Hosseini, H. Monirpour, Nader (2020). The effect of imaginary visualization on activation of release schema and reduction of interpersonal dependence in individuals with extreme avoidance and compensation styles. Journal of Psychological Science, 19 (91), 923-917. (Persian). [Link]

Lovell, G., \& Collins, D. (2001). Speed of image manipulation, imagery ability and motor skill acquisition. International Journal of Sport Psychology, 32, PP: 355-368. [Link]

Malouin, F., Richards, C., Jackson, P. L., Dumas, F., Doyon, J. (2003). Brain activations during motor imagery of locomotor-related tasks: A PET study. Human Brain Mapping, 19, PP: 47-62. [Link]

Marletz M. (1993). Psychology imagery. Translated: Gharachedaghi M.12 Publishers Shabahang; asrare nhkesh. P 35. [Link]

Miller, K. j, Schalk, G., Ftz, E. E., Rao, R. P. (2010). Cortical activity during motor execution, motor imagery, and imagery-based online feedback. 2, 107(9): PP: 4430-5. [Link]

Miller, K. J. (2007). Spectral changes in cortical surface optional during motor movement. Journal of Neuroscience; (27): PP: 2424-2432. [Link]

Moran, A. (2009). Cognitive psychology in sport: Progress and prospects. Psychology of Sport and Exercise; (10): PP: 420-426. [Link]

Morris T. M, Spittle P, Anthony p. (2005). Imagery in sport: The mental approach to sport. Human Kinetics; 3 champaien. PP: 344-83. [Link]

Mulder, T. (2007). Motor imagery and action observation: cognitive tools for rehabilitation. Journal of Neural Transmission, 114(10), PP: 1265-1278. [Link]

Murphy, S. h., Nordin, S., Cumming, J. (2008). Imagery in Sport, Exercise, and Dance. Journal of Sport Psychology, (29): PP: 2424-2432. [Link]

Natio, E., kochiyama, T., Kitada, R., Nakamura, S., Matsumara, M., Yonekure, Y. (2002). Internally simulated movement sensations during motor imagery activate cortical motor areas and the cerebellum. Journal of Neuroscience. (22): PP: 3683-3691. [Link]

Overdrf, V. (2004). Mental and physical practice schedules in acquisition and retention of novel timing skills: Perceptual \& Motor skills. (1): PP: 51-62. [Link]

Piaget, J., \& Inhelder, B. (1966). L'image mentale chez L'Enfant, étude sur le développement des représentations imagées. [Mental image in thé child, study on the development of imaged representation.] PUF. Paris: Saint-Germain. [Link]

Piaget, J., \& Inhelder, B. (1971). Mental imagery in the child: A study of the development of imaginai representation (P. A. Chillón, Trans.). London: Routledge \& Kegan Paul. [Link]

Piaget, J., \& Inhelder, B. (1981). La représentation de l'espace chez 1 'enfant. [Spatial representation in the child.] PUF. Paris: SaintGermain. [Link]

Schmidt, R. A. (1975). A schema theory of discrete motor skill learning. Psychological Review, 82, PP: 225260. [Link]

Schmidt, R.A., Lee, T.D. (2005). Motor control \& Learning. Human kinetics, PP: 410-430. [Link]

Seger, C. A. (2006). The basal ganglia in human learning. Neuroscientists; (12): PP: 285-290. [Link]

Shapiro, D. C., Schmidt, R. A. (1982). The schema theory: Recent evidence and developmental implications. In J. A. S. Kelso \& J. E. Clark (Eds.), the development of movement control and Coordination, pp: 113-150. New York: Wiley. [Link]

Smith, D., Wright, C., Allsopp, A. and Westhead, H. (2007). It's all in the mind: PETTLEP-based imagery and sports performance. Journal of Applied Sport Psychology, 19, PP: 80-92. [Link]

Taktek, K. (2004). The effects of mental imagery on the acquisition of motor skills and performance: A literature review with theoretical implications. Journal of Mental Imagery, 2S (1\&2), PP: 79-114. [Link]

Taktek, K. (2006). Mental representation: Fundamental principles and ontogenetic perspectives. Journal of Mental Imagery, 30(।\&2), PP: 125-162. [Link]

Taktek, K., \& Hochman, J. (2004). Ahsen Triple Code Model as a solution to some persistent problems within Adams' closed loop theory and Schmidt's motor schema theory. Journal of Mental Imagery, 28(1\&2), PP: 115-158. [Link]

Taktek, K., \& Rigai, R. (2005). Stratégies pédagogiques et apprentissage d'une tâche motrice discrète chez des enfants de huit à dix Ans. [Pedagogical strategies and learning of a discrete motor task in children 8 to 10 years of age.] Revue des Sciences de l'Éducation, 31, PP: 607-632. [Link]

Taktek, Kh. Zinsser, N. St-John. B.( 2008).Visual versus Kinesthetic Mental Imagery: Efficacy for the Retention and Transfer of a Closed Motor Skill in Young ChildrenCanadian. Journal of Experimental Psychology.. 62, Iss. 3; pg. 174, 14 pgs. [Link] 
Vealey R S, Greenleaf C. A. (2001). Seeing is believing: Understanding and using imagery in sport. In Journal Williatns Education, applied sport psychology: personal growth to peak performance. 2(5): 237- 69. [Link]

Williams, S. E., Cooley, S. J., and Cumming, J. (2013). Layered stimulus response training improves motor imagery ability and movement execution. J. Sport Exerc. Psychol. 35, PP: 60-71. [Link]

Williams, S. E., Cumming, J., Ntoumanis, N., NordinBates, S. M., Ramsey, R., \& Hall, C. (2012). Furthervalidation and development of themovement imagery questionnaire. Journal of Sport \& ExercisePsychology, 34, PP: 621-646. [Link] 